\title{
Size- and Shape-Controlled Synthesis of Monodisperse Metal Oxide and Mixed Oxide Nanocrystals
}

\author{
Thanh-Dinh Nguyen and Trong-On Do \\ Department of Chemical Engineering, Laval University, Quebec
}

Canada

\section{Introduction}

A nanocrystal or nanoparticle (not fully crystalline) is defined as a particle with size in range of 1 to $100 \mathrm{~nm}$ (102 to $10^{7}$ atoms) from zero (0D) to three dimensions (3D), which exhibits the unique physiochemical properties due to the quantum size effect that cannot be anticipated from bulk counterparts. Strictly speaking, the name of "nanocrystal" is only used for crystalline nanoparticle, and is however a more general term which can refer to both crystalline and non-crystalline nanoparticles. Accordingly, their particle size is intermediate between the size of molecule and bulk solid (Rao, Müller and Cheetham 2005, Sorensen 2009). Nanocrystals can be formed in a variety of shapes including dot, sphere, cube, rod, triangle, hexagon and many others. In this size range, they possess an immense surface area per unit volume, a very large percentage of atoms in the surface. As a result, their unexpected properties can be obtained as compared to those of both individual atoms/molecules and bulk counterpart of the same chemical composition.

Size- and shape-dependent properties of the nanocrystals can be tuned by changing the dimension and designing the shape (Rao et al. 2005). Due to the materials at the nanoscale, low coordination number, surfaced edge and corner atoms are usually chemically reactive, catalytically active and polarisable surface, contributing to their high chemical potential. For example, the high surface area is of particular importance regarding heterogeneous catalytic reactions, because of the increase of interaction of reactive molecules and active sites on the catalyst surface (Abbet and Heiz 2005). Furthermore, the particle size not only affects their surface area, but also arise new properties, due to the quantum-size effect (e.g., electron confinement and surface effect) (Kroes et al. 2002, Kamat et al. 2010).

Considerable efforts have recently been devoted to the preparation of metal oxide and mixed oxide nanomaterials due to both their unique properties and their technological applications (Seshadri 2005, Burda et al. 2005, Mao et al. 2007, Yin and Alivisatos 2005). Metal oxides including the transition metals and rare earths, display a wide variety of complex structures and interesting electronic and magnetic properties associated with the changes in electronic structure and bonding and in the presence of ordered defect complexes or extended defects. The nanostructured mixed oxides can greatly generate new synergetic properties and improve the overall application performance, that is not available from single metal oxide species, due to the appropriate combination of individual oxide 


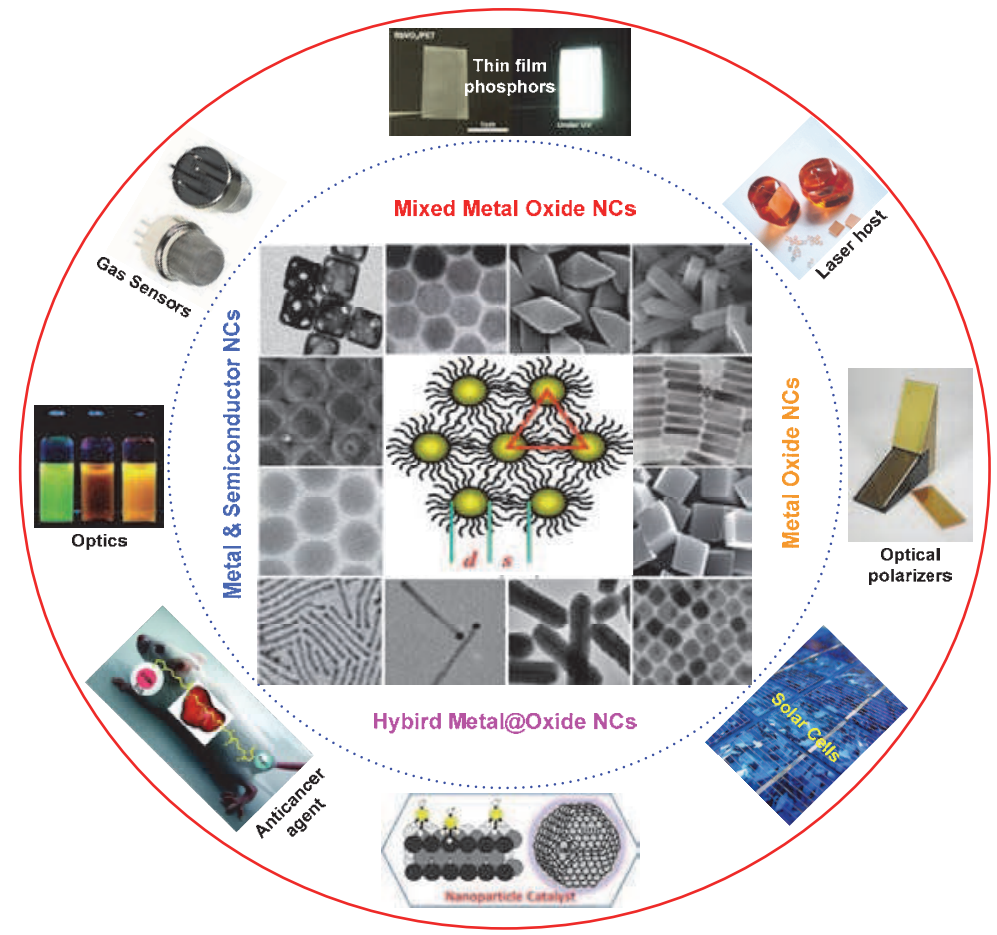

Fig. 1. Representative shapes of inorganic nanocrystals developed to date. These kinds of nanocrystals utilized as key building blocks for the fabrication of novel nano-systems for catalytic, electronic, and biomedical technologies.

components (Redl et al. 2003). Furthermore, the size- and shape-dependent properties of nanomaterials raising expectations for a better performance generally are a consequence of quantum confinement within the particle (Alivisatos 1996). The precise controlled synthesis of the size, shape, chemical composition, crystal structure, and surface chemistry of nanomaterials allows to obtain their unique properties, which have become one of the most challenging issues faced by nanomaterial researchers. The properties of nanocrystals are drastically altered in the shape and size change, making nanocrystals as ideal candidates for many applications, such as in catalysis, energy storages, optoelectronics, sensing, magnetic resonance imaging, biomedicine. (Jun, Choi and Cheon 2006b, Hao et al. 2010, Kinge, CregoCalama and Reinhoudt 2008, Ying 2000, Na, Song and Hyeon 2009, Jun, Choi and Cheon 2006a). A general picture in Figure 1 is schematically illustrated for the features and new phenomena of the nanoscale materials.

The size- and shape-dependent properties of colloidal metal oxide and mixed oxide structures at the nanoscale makes great demands to the synthetic methodology. Therefore, it is a great challenge to develop a "synthetic chemistry" of nanocrystals that is as precise as that used to make building units. This allows scientists to study the effect of these synthesis parameters which impart to the unique collective properties of monodisperse nanocrystals. There are two different approaches to synthesize nanocrystals: the "top-down" approach, which utilizes physical methods, and the "bottom-up" approach, which employs solution- 
phase colloidal chemistry. Using the top-down approach, the production of a large quantity of nanocrystals can be achieved, however, uniform-sized nanocrystals and their size control is very difficult to obtain. In contrast, using the "bottom-up" approach, the colloidal chemical methods can be used to synthesize uniform nanocrystals with controlled particle size through chemical nucleation and growth process in bulk solution, although generally only subgram quantities are produced (Schmid 2005). The use of atoms or molecules as building blocks has the advantage, that provides control over crystallite size and shape with a precision well beyond that of top-down lithography (Park et al. 2007). Indeed, bottom-up assembly of well-defined nanoscale building blocks into nanocrystals with controlled size and shape represents a powerful tool to fabricate novel multi-component materials and devices (Nagarajan 2008). In order to control the crystal growth, the capping agents are often used to decrease the surface energies of crystals. The surfactants bind selectively to the different crystallographic faces, so that shape of nanocrytals can be controlled by the nonselective or selective surfactants (2008, Cushing, Kolesnichenko and O'Connor 2004). The use of surfactant molecules, and consequently, result in oxide nanocrystals comprising an inorganic core coated with a layer of organic surfactant molecules. This organic capping provides electronic and chemical passivation of the surface dangling bonds, prevents uncontrolled growth and agglomeration of the nanoparticles, and permits chemical manipulations of the nanoparticles similarly to large molecules having their solubility and reactivity determined by the nature of the surface ligands. The most commonly used ones in colloidal syntheses include alkyl- thiols, long chain amines, carboxylic and phosphonic acids, phosphine oxides, phosphine, phosphates, phosphonates, and various coordinating (e.g., ethers, THF, DMF) or non-coordinating solvents (e.g., alkanes, alkenes).

Understanding growth behavior and morphology evolution is crucial for an efficient synthesis and a good control of inorganic nanocrystals. In the bottom-up syntheses, for the growth process of nuclei, the behavior was described by the classical Ostwald ripening mechanism, in which the growth of larger particles at the expense of smaller ones driven by surface energy reduction. This phenomenon was extensively used to explain the formation of thermodynamically stable nanocrystals with nearly spherical morphologies. For the controlled self-assembly of nanoparticles into well-defined anisotropic nanostructures, organic capping reagents usually play critical roles in reducing the activity of the nanocrystal surface to promote or tune the ordered self-assembly (Kinge et al. 2008, Sellinger et al. 1998, Malenfant Patrick et al. 2007, Yin and Alivisatos 2005). An oriented attachment mechanism could offer as an additional tool to design advanced materials with anisotropic properties and could be used for the synthesis of more complex crystalline onedimensional structures. In addition, the sterically diffusive kinetics and selective binding or nonbinding of surfactant molecules to different faces of the growing nanocrystal can also control the product's morphology due to the possibility of breaking the limitations of crystal growth dynamically. In some cases, the formation of the intrinsic anisotropic nanocrystals is found to be a highly kinetics-driven process, which occurs far away from the thermodynamic equilibrium, and must be overdriven by high precursor monomer concentrations.

The reaction medium is crucial in the solution-based approaches. To date, noble metal nanocrystals obtained from solution-based methods that mainly used the organic reagent as solvent medium such as toluene, diphenyl ether, oleic acid/oleylamine, etc. In organic solvent systems, expensive organometallic precursors, toxic and environmentally unfriendly organic solvents are often not compatible with biomedical applications. Water, as an 
environmentally friendly solvent with the most abundant resource, and most metal nitrates and chloride salts were used as starting materials, can overcome these barriers. Further, due to the high solubility of metal salt precursors in aqueous media, the aqueous-based routes can be used for the synthesis of pure products in high yield. Therefore, the development of general synthetic strategies to produce the size- and shape-controlled metal oxide, mixed oxide nanocrystals in terms of low cost, environmentally benign reagents, mild synthesis conditions, and potential for large-scale production are needed among the important research topics of the advanced materials chemistry.

In the present chapter, we provide a brief account of our own recent results to synthesize different types of monodisperse colloidal metal oxide and mixed oxide nanocrystals, focusing on one-phase and two-phase solvo-hydrothermal surfactant-assisted approaches. Based on our approaches, a variety of metal oxide and mixed oxide nanocrystals with different sizes, shapes, and phases are obtained using simple chemical reactions (e.g., solvohydrothermal reactions), choosing appropriate reaction systems (precursor, surfactant.), and controlling reaction parameters (monomer concentration, temperature and time). The chapter is organized as follows: Introduction in Section 1; Essential concepts in the nucleation and crystal growth process of size- and shape-controlled nanocrystals in Section 2; subsequently, we present the main results in our laboratory along with the results from other research groups related to metal oxide nanocrystals in Section 3, followed by mixed metal oxide nanocrystals in Section 4 . The synthetic procedures, the formation mechanisms, and the controlled growth of nuclei based on kinetic and thermodynamic conditions as well as the selection of capping agents will also be discussed to control the size and shape, and conclusion in Section 5.

\section{General strategies for surfactant-assisted synthesis of colloidal metal oxide and mixed oxide nanocrystals}

In a typical synthesis of inorganic nanocrystals, the precursor compound in bulk solution is decomposed to generate atoms followed by the precipitation starting from dissolved atoms as building blocks to form the nanocrystals. A understanding of the process and parameters controlling the precipitation helps to improve the engineering of the growth of nanocrystals to the desired size and shape. The precipitation process then basically consists of a nucleation step followed by crystal growth stages. Generally, there are three kinds of nucleation processes: homogeneous nucleation, heterogeneous nucleation, and secondary nucleation. For the chemical colloidal nanocrystal synthesis, homogeneous nucleation occurs in the absence of a solid interface by combining solute molecules to produce nuclei. Homogeneous nucleation occurs due to the driving force of the thermodynamics because the supersaturated solution is not stable in energy. Seed formation proceeds according to the LaMer model are shown in Figure 2. This mechanism reported in the early 50's on the basis of the crystallization study of the solution-phase synthesis of monodisperse sulfur colloids in ethanol (LaMer and Dinegar 1950). According to LaMer plot for the crystal nucleation process, in which the concentration of atoms steadily increases with time as the precursor is decomposed by heating, colloidal nanocrystal formation comprises the following three steps: (i) The atoms start to aggregate into nuclei via self-nucleation as increasing the monomer concentration in the solution to supersaturation levels; (ii) Then monomers continuously aggregate on the pre-existing nuclei or seed which leads to gradual decrease in the monomer concentration. As long as the concentration of reactants is kept below the 
critical level, further nucleation is discouraged; (iii) With a continuous supply of atoms via ongoing precursor decomposition, the nuclei will grow into nanocrystals of increasingly larger size until an equilibrium state is reached between the atoms on the surface of the nanocrystal and the atoms in the solution (Watzky and Finke 1997).

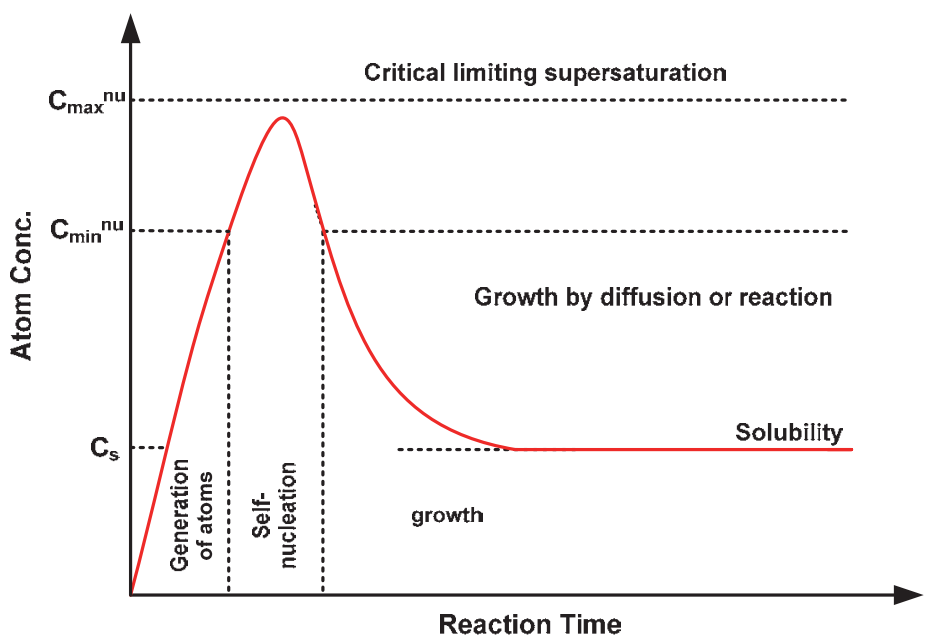

Fig. 2. Plot of La Mer model for the generation of atoms, nucleation, and subsequent growth of colloidal synthesis (LaMer and Dinegar 1950)

After the formation of nuclei, the subsequent growth stages also strongly govern the final morphology of the nanocrystals. Generally, the nanocrystal growth can occur under two different regimes, either in a thermodynamically controlled or kinetically controlled growth regime. The manipulation between thermodynamic and kinetic growth regimes is thus a critical factor in determining nanoparticle shape (Kwon and Hyeon 2009) The final nanoparticle morphology can be controlled by dictating the shape of nuclei and directing the growth of the nuclei and/or nanocrystals. Nuclei can take on a variety of shapes determined by the chemical potentials of the different crystallographic faces, which are in turn highly dependent on the reaction environment such as temperature and solute concentration. The nuclei shape can have a strong effect on the final nanocrystal shape, for example, through selected growth of high-energy crystal faces of the nuclei (Skrabalak and Xia 2009, Pileni 2007, Searcy 1983). In the present of surfactant in bulk solution, the products are capped by surfactant molecules, resulting in the restriction of the particle growth as well as the good dispersibility of the product in reaction solvent. This is particularly important for shape control: to obtain a highly shape-monodisperse yield of nanocrystals, nucleation must occur rapidly and instantaneously.

The surfactant-assisted synthetic methods provide convenient and powerful pathway for the reproducible controlled synthesis of nanocrystals because these methods allow for the metal oxide and mixed oxide nanocrystals to be precisely adjusted in terms of their size, shape, composition, and phase structure on the nanometer scale. Nanocrystals obtained by the surfactant-assisted route, in general, exhibit excellent crystallinity and monodispersity. In the following section, we develop the simple one-phase and two-phase surfactant- 
assisted routes for the shape-and size-controlled synthesis of colloidal monodisperse metal oxide and mixed metal oxide nanocrystals.

Critical reaction parameters that have strong effect on the growth of the metal oxide and mixed oxide nanocrystals including precursor and surfactant concentration, the molar ratio of precursor to capping ligand, and reaction temperature and time, are precisely adjusted to control over their sizes and shapes in the crystal nucleation-growth stages. In addition, to understand the formation process of nanocrystals in the bulk solution, we discuss the possible mechanism for the shape and size control of the nanocrystals obtained from our surfactant-assisted approaches. In all cases, there are some advantages for these routes because of the use of inorganic salt precursors, instead of expensive metal alkoxides, and quite mild synthetic conditions. Particularly, these synthesis methods are scalable to multigram in a single run using the same synthetic conditions.

\section{Metal oxide nanocrystals}

Within the broad family of functional materials, metal oxides play a very important role in many scientific and technological areas (Lu, Chang and Fan 2006) For decades they have been extensively investigated their physiochemical properties and useful applications by solid-state chemists. Metal oxides including the transition metals and rare earths are able to form a large diversity of oxide compounds, giving the inspiration for designing new materials. The crystal structures ranging from simple rock salt to complex oxide are often built by the metal-oxygen bonds varying nearly ionic to covalent or metallic. The oxidic materials exhibit fascinating electronic and magnetic properties associating with the changes in electronic structure and bonding (Gariglio, Gabay and Triscone 2010). Additionally, metal oxides having multivalent oxidation states have attracted much attention among specialists because they often exhibit superior catalytic reaction performance (Antonini and et al. 1987) Many progresses, such as hot injection, co-precipitation, microemulsion, nonhydrolytic solgel process, and so on, have been devoted to fabricate metal oxide nanocrystals.

Vanadium oxides $\left(\mathrm{V}_{2} \mathrm{O}_{5-x}\right)$ are of interest due to their versatile redox activity and layered structures (Shah et al. 2008) They are a key technological material widely used in various fields such as chemical sensing (Livage 1991), actuators (Gu et al. 2003), high-energy lithium batteries (Poizot et al. 2000), and electric field-effect transistors (Muster et al. 2000) As a target for the shape-controlled NC synthesis, recent studies in vanadium oxide NCs have focused on the development of synthetic approaches toward nanotubes, nanobelts, nanofibers, nanowires, nanorods, and so on, as well as their shape-dependent properties. Recently, our group demonstrated a simple modified solvothermal method for the multigram scale synthesis of uniform vanadium oxide NCs using vanadium(V) diperoxo alkylammonium complexes in toluene or toluene/water medium in the presence of aliphatic amines as capping agent (Nguyen and Do 2009b) The V(V) diperoxo tetraoctylammonium complexes, $\mathrm{VO}\left(\mathrm{O}_{2}\right)_{2}(\mathrm{TOA})$, were prepared from the two-phase system of $\mathrm{V}(\mathrm{V})$ diperoxo aqueous solution and toluene containing tetraoctylammoniumligands $\left(\mathrm{TOA}^{+}\right)$(Figure $3 \mathrm{~A}$ ). Under the solvothermal treatments, $\mathrm{VO}\left(\mathrm{O}_{2}\right)_{2}(\mathrm{TOA})$ complex precursors are decomposed and generate vanadium monomers and then grew into vanadium nanocrystals. They are capped by oleylamine molecules and easily dispersed in organic medium. The XRD results revealed that the as-made vanadium oxide nanocrystal samples corresponds to monoclinic rutiletype $\mathrm{VO}_{2}$ structure. However, the XRD pattern of the calcined sample exhibits the orthorhombic $\mathrm{V}_{2} \mathrm{O}_{5-x}$ structure. Furthermore, their color changed from blue-black to yellow 
after calcination. This indicates the transformation from the monoclinic rutile phase to the orthorhombic phase of these samples.

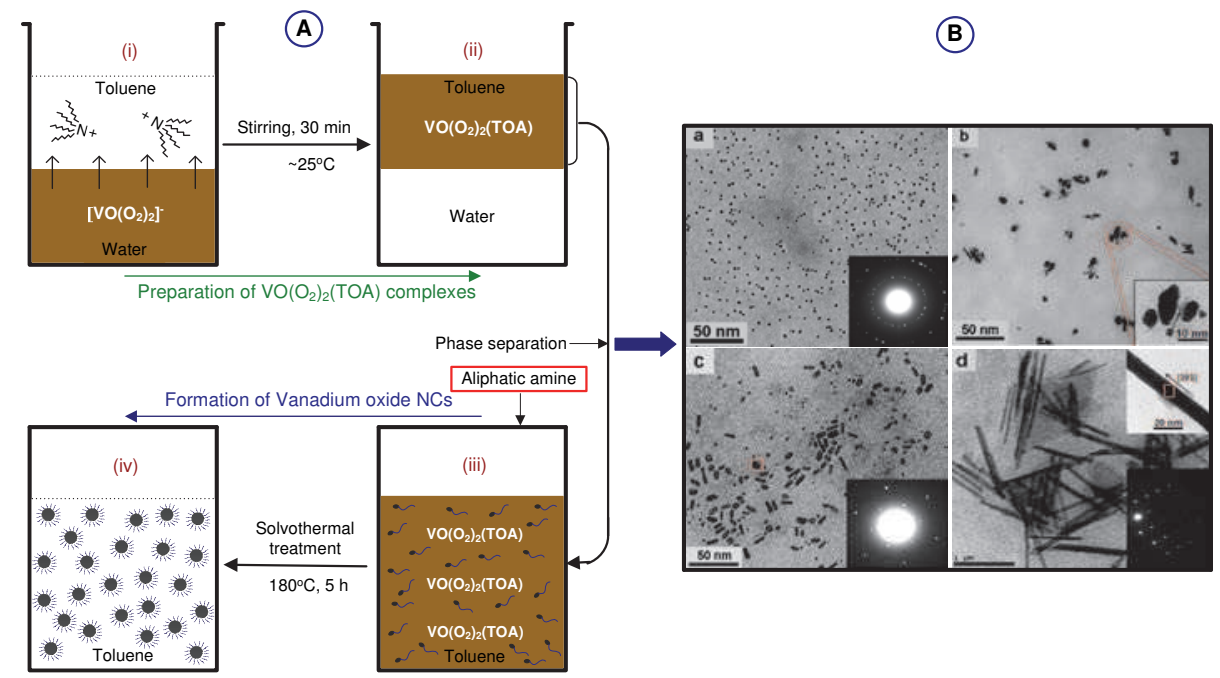

Fig. 3. (A) Schematic illustration of the preparation of vanadium(V) diperoxo

tetraoctylammonium $\left(\mathrm{VO}(\mathrm{O})_{2}(\mathrm{TOA})\right.$ complexes, followed by the formation of alkyl aminescapped vanadium oxide nanocrystals; (B) Effect of water content in the synthesis mixture on the shape transformation of nanospheres into nanorods. TEM images and corresponding SAED patterns of the as-made $\mathrm{VO}_{2}$ nanocrystals synthesized from $\mathrm{V}(\mathrm{V})$ diperoxo tetraoctylammonium complexes $(0.04 \mathrm{~mol} / \mathrm{L})$ in oleylamine $(5 \mathrm{~mL})$ at $180{ }^{\circ} \mathrm{C}$ for $5 \mathrm{~h}$ with various water/toluene solvent ratios in volume $(\mathrm{W} / \mathrm{T})$ : a) $\mathrm{W} / \mathrm{T}=0: 40, \mathrm{~b}) \mathrm{W} / \mathrm{T}=2: 40, \mathrm{c}$ ) $\mathrm{W} / \mathrm{T}=8: 40$, and $\mathrm{d}$ ) $\mathrm{W} / \mathrm{T}=20: 40$ (Nguyen and Do 2009b)

The monodisperse vanadium oxide NCs with different sizes and shapes including nanospheres, nanocubes, nanorices, and nanorods can be achieved by the control of various reaction parameters, such as types of $\mathrm{V}(\mathrm{V})$ diperoxo alkylammonium complexes, and alkyl chain length of capping agents in synthesis mixture. Remarkably, a significant effect of water content on the size and shape of vanadium oxide NCs has been observed. Figure 3B shows representative TEM images of these samples synthesized at different water/toluene volume ratio $(\mathrm{W} / \mathrm{T})$ varing from $0: 40$ to $2: 40,8: 40$, and 20:40. Only uniform quasispherical NCs with an average size of $4 \mathrm{~nm}$ were obtained in the absence of water in the synthesis medium. While the $\mathrm{W} / \mathrm{T}$ value was as low as 2:40, aggregated nanoparticles beside some un-uniformed small nanorods were formed. When the $\mathrm{W} / \mathrm{T}$ value increased to $8: 40$, mostly short vanadium oxide nanorods were generated. However, when the $\mathrm{W} / \mathrm{T}$ value increased to 20:40, the vanadium product is composed of uniformly sized and shaped rods with $20 \mathrm{~nm}$ in width and 150-300 $\mathrm{nm}$ in length. The SAED pattern taken from a single vanadium oxide nanorod reveals the single crystal nature of the nanorod, and it further confirmed that the nanorods' elongation axis was along the [101] direction. The shape elongation of vanadium oxide nanocrystals in the increase of water could be explained by a lateral aggregation of individual nanorods along the longitudinal axis and further their fusion to form aligned nanorods at the high water content in the synthesis mixture. 
Some research groups reported the preparation of size-turnable $\mathrm{VO}_{\mathrm{x}}$ nanotubes via the aging and hydrothermal process of various vanadium sources including bulk $\mathrm{V}_{2} \mathrm{O}_{5}$ powders, vanadium(V) peroxo gels, and vanadium(V) triisopropoxides using aliphatic amines as structure-directing templates (Tenne 2004, Spahr et al. 1998, Corr et al. 2008) Schlogl et al. (Pinna et al. 2003) presented a reverse micelle technique to prepare $\mathrm{V}_{2} \mathrm{O}_{5}$ nanorods and nanowires from a colloidal self-assembly made of sodium bis(ethyl-2hexyl)sulfosuccinate $\mathrm{Na}(\mathrm{AOT}) /$ isooctane $/ \mathrm{H}_{2} \mathrm{O}$. Park et al. (Guiton et al. 2004) synthesized single-crystalline $\mathrm{VO}_{2}$ nanowires with rectangular cross sections using a vapor transport method. Zhang et al. (Li et al. 2007) showed that the belt-, olive-, petal-shaped $\mathrm{VO}_{2} \mathrm{NCs}$ could be synthesized with high concentrations of the reducing oxalic acid agent through the hydrothermal route. Baughman et al. (Gu et al. 2003) reported the synthesis of $\mathrm{V}_{2} \mathrm{O}_{5}$ nanofibers at room temperature from ammonium metavanadate and acidic ion-exchange resin in water. The resulting $\mathrm{V}_{2} \mathrm{O}_{5}$ nanofibers could deliver dramatically higher specific discharge capacities than micrometer-sized $\mathrm{V}_{2} \mathrm{O}_{5}$ fibers. The Whittingham's group has also developed a method to produce vanadium oxide nanofibers with dimensions of less than $140 \mathrm{~nm}$ by coating oxides on polylactide fibers (Lutta et al. 2005).

Erbium-compound nanomaterials consisting of hexagonal $\mathrm{Er}(\mathrm{OH})_{3}$, monoclinic ErOOH, or cubic $\mathrm{Er}_{2} \mathrm{O}_{3}$ are particularly attractive among the rare earth oxides due to their remarkably electrical and optical properties. These unique properties orginate from the intra $\mathrm{Er}^{3+} 4 f$ shell transition from its first excited state $\left({ }^{4} I_{3 / 2}\right)$ to the ground state $\left({ }^{4} I_{5 / 2}\right)$ is related to the emission band of around $1.54 \mu \mathrm{m}$, which is one of the standard telecommunication wavelengths. As a consequence, this minimum absorption has become ideal candidates for use in lasers and optical amplifiers for sensing applications. However, little work has been reported concerning 3D erbium compound materials with controllable size, from micro- to nanostructures, and shapes such as spheres, wrinkle-surfaced spheres, and flowers. Recently, we successfully synthesized the erbium-compound micro- and nanostructures consisting of $\mathrm{Er}(\mathrm{OH})_{3}, \mathrm{ErOOH}$, and $\mathrm{Er}_{2} \mathrm{O}_{3}$ from the reaction of erbium nitrate in basic solution containing ethanol/decanoic acid via ligand-assisted hydrothermal route (Figure 4A) (Nguyen, Dinh and Do 2010). The reactions take place in a water/ethanol solution, a "one polar phase" system at the relatively low temperature of $\leq 180{ }^{\circ} \mathrm{C}$. The capping products were precipitated at the bottom of a Teflon cup instead of becoming dispersed in the toluene phase as described in the previous two-phase methods. A central feature of this work is the generation of products in the morphology, composition, and phase structure control, which is simple, economical, versatile, and using water as an environmentally benign solvent. As shown Figure 4B, by only tuning the temperature in the reaction system, monoclinic ErOOH and cubic $\mathrm{Er}_{2} \mathrm{O}_{3}$ phases can be obtained. Furthermore, various particle sizes in the range of thousands to tens of nanometers and a variety of shapes can be achieved simply by varying the synthetic conditions including the concentration of decanoic acid and erbium precursor and the amount of water. The crystalline phase- and particle sizedependent luminescence results indicated that the luminescence properties depend not only on the crystalline phase but also on the particle size of products. The luminescence intensity increases with a decrease of particle size.

Li et al. (Wang et al. 2005b) reported a general hydrothermal method for the synthesis of a variety of nanocrystals by a liquid-solid-solution reaction. The system consists of metal salt, sodium linoleate (solid), ethanol-linoleic acid liquid phase and water-ethanol solution at different reaction temperatures under hydrothermal conditions. $\mathrm{TiO}_{2}$ nanoparticles and nanorods can be also obtained by solvothermal reaction of titanium butoxide, linoleic acid, 
triethylamine, and cyclohexane ( $\mathrm{Li}$ et al. 2006). The decomposition of $\mathrm{NH}_{4} \mathrm{HCO}_{3}$ which provide $\mathrm{H}_{2} \mathrm{O}$ for the hydrolyzation reaction is found to be an important factor to shape evolution of particles. In the presence of $\mathrm{NH}_{4} \mathrm{HCO}_{3}$, the fast hydrolyzation of precursors with the water leads to the formation of nanoparticles. In the absence of $\mathrm{NH}_{4} \mathrm{HCO}_{3}$, in contrast, the slow nonhydrolytic condensation of precursors produces titania nanorods with uniform diameters of $3.3 \mathrm{~nm}$, and a length of up to $25 \mathrm{~nm} . \mathrm{TiO}_{2}$ nanowires could be also produced by solvothermal treatment of a mixture containing titanium tetra-isopropoxide, ethylenediamine, and ethylene glycol (Xie and Shang 2007). The diameter of nanowires was controlled by changing the amount of ethylenediamine.

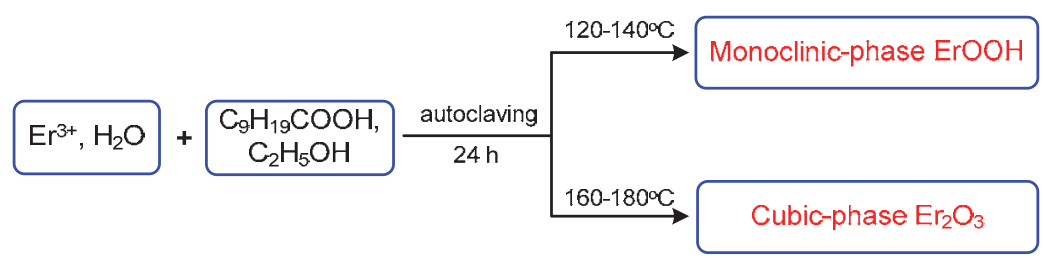

(a)

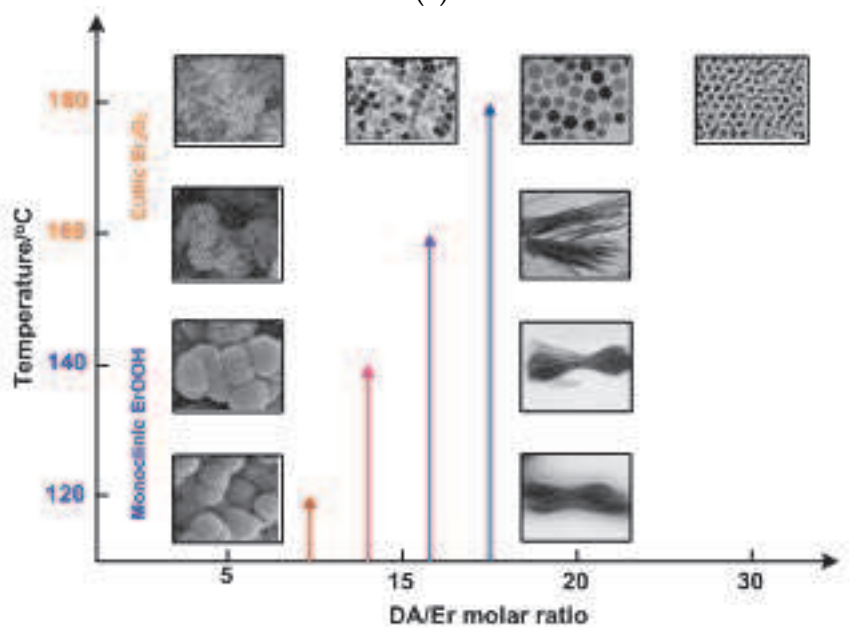

(b)

Fig. 4. (a) A general synthetic procedure for controlled size, shape, and phase of erbiumcompound micro- and nanostructures; (b) ErOOH and $\mathrm{Er}_{2} \mathrm{O}_{3}$ micro- and nanostructures with different sizes, shapes, and phases obtained as a function of reaction temperature and decanoic acid/erbium molar ratio (Nguyen et al. 2010)

Our group recently also synthesized the $\mathrm{TiO}_{2}$ nanocrystals with well-controlled shapes on the basis of solvothermal technique using both acid oleic acid (OA) and oleyamine (OM) as two capping surfactants, and water vapor as hydrolysis agent (Dinh et al. 2009). It is demonstrated that, the presence of water vapor along with the desired OA:OM molar ratio plays crucial roles in controlling size and shape of $\mathrm{TiO}_{2}$ nanocrystals. In particular, the shape of $\mathrm{TiO}_{2}$ changed from rhombic to truncated rhombic and to sphere as the OA:OM ratio increased from 4:6 to 5:5 and to 6:4, respectively. Increasing the amount of titanium butoxide 
(TB) led to the formation of elongated particles. For example, when the TB:OA:OM molar ratio changed from 1:6:4 to 2:6:4, the shape of $\mathrm{TiO}_{2}$ evolved from spheres to dog bone-like particles with uniform size. The solvothermal reaction of $\mathrm{Mn}\left(\mathrm{NO}_{3}\right)_{2} /$ oleylamine/dodecanol recently flourished by $\mathrm{Li}$ et al. ( $\mathrm{Li}$ et al. 2010b) was a successful way for shape control of highly monodisperse $\mathrm{Mn}_{3} \mathrm{O}_{4}$ nanocrystals with dot, rod, wire shapes. Moreover, the asprepared hydrophobic spherical or elongated nanoparticles were used as building blocks to be rationally assembled into three-dimensional (3D) $\mathrm{Mn}_{3} \mathrm{O}_{4}$ colloidal spheres with a facile ultrasonication strategy. The as-prepared colloidal spheres were chemically converted to $\mathrm{LiMn}_{2} \mathrm{O}_{4}$ nanomaterials in a simple solid-state reaction. Such materials showed distinct electrochemical performance, mainly depending on their crystallinity and particle size.

The Niederberger's group developed a nonaqueous sol-gel approach for the synthesis a variety of metal oxide nanocrystals involving the solvothermal treatment of metallic alkoxide precursors in benzyl alcohol solvent (Garnweitner and Niederberger 2008). As the presence of halide impurities in the final oxides obtained by these routes may be a drawback, alternative halide-free methods have been developed as well.

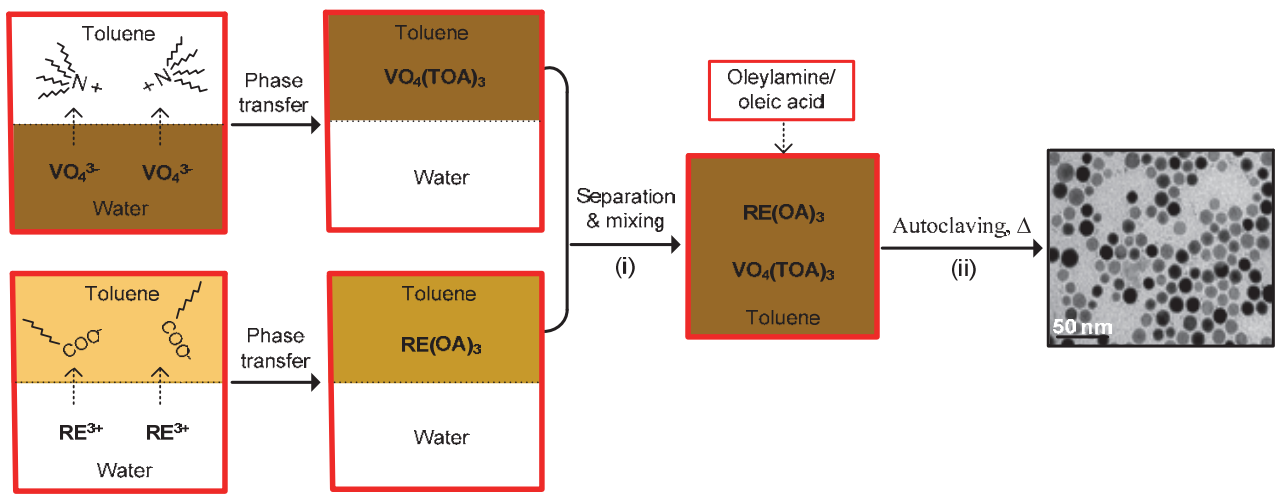

Fig. 7. Schematic illustration for the formation of the $\mathrm{RE}(\mathrm{OA})_{3}$ and $\mathrm{VO}_{4}(\mathrm{TOA})_{3}$ complexes (i) and the $\mathrm{REVO}_{4}$ nanocrystals (ii) (Nguyen et al. 2009a, Nguyen et al. 2009b)

The shape of $\mathrm{SmVO}_{4}$ and $\mathrm{CeVO}_{4} \mathrm{NCs}$ can be controlled by the synthesis temperature. TEM images of the samples synthesized solvothermally at $150^{\circ} \mathrm{C}$ and $180^{\circ} \mathrm{C}$ for $16 \mathrm{~h}$ are shown in Figures 8a,b (Nguyen et al. 2009a). Nearly cubic-shaped $\mathrm{SmVO}_{4}$ and round-shaped $\mathrm{CeVO}_{4}$ nanocrystals with an average diameter of $15 \mathrm{~nm}$ were found at $150{ }^{\circ} \mathrm{C}$. When the synthesis temperature increased to $180{ }^{\circ} \mathrm{C}$ for $16 \mathrm{~h}$, both uniform $\mathrm{SmVO}_{4}$ and $\mathrm{CeVO}_{4}$ nanospheres were observed, however, the diameter is unchanged. The transformation of both cubicshaped $\mathrm{SmVO}_{4}$ and round-shaped $\mathrm{CeVO}_{4} \mathrm{NCs}$ into uniform nanospheres, while preserving the particle size by increasing synthesis temperature from $150^{\circ} \mathrm{C}$ to $180^{\circ} \mathrm{C}$ can be explained by Wuff facets theory. The XPS results for characterization of these nanomaterials exhibite that only one oxidation state of samarium, cerium, and vanadium for each metal (e.g., $\mathrm{Sm}^{3+}$, $\mathrm{Ce}^{3+}, \mathrm{V}^{5+}$ ) was observed on the particle surface at the nanoscale, even after calcination, while the existence of two oxidation states of these metals was found (e.g., $\mathrm{Sm}^{3+} / \mathrm{Sm}^{2+}, \mathrm{Ce}^{4+} / \mathrm{Ce}^{3+}$, $\mathrm{V}^{5+} / \mathrm{V}^{4+}$ ) in the corresponding single metal oxide nanocrystals (Nguyen et al. 2009a).

For this approach, $\mathrm{SmVO}_{4}$ was selected as a typical example for discussion on the experimental results. It was found that their size and shape were controlled by the nature 


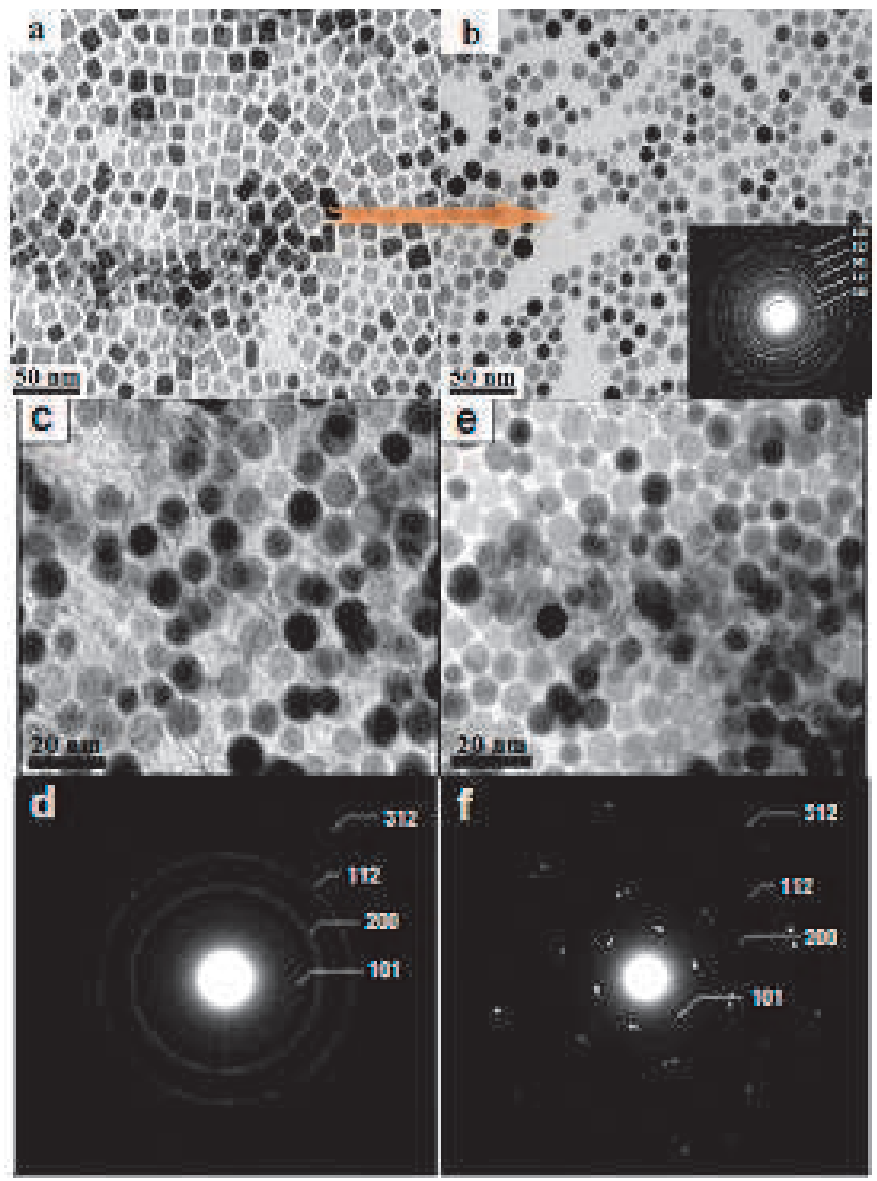

(g)

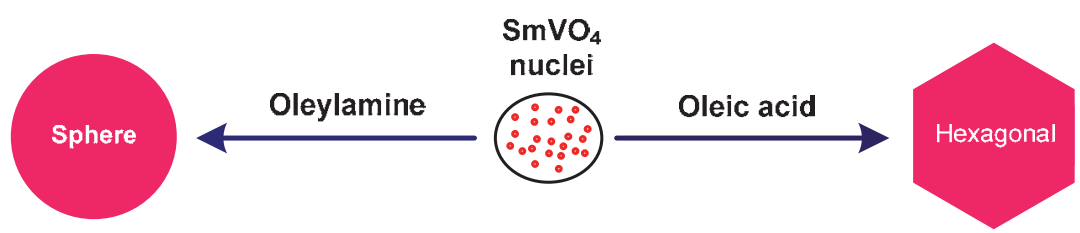

Fig. 8. Effects of the reaction temperature and surfactants with different functional groups on the shape control. TEM images of $15 \mathrm{~nm}$-sized $\mathrm{SmVO}_{4}$ nanocrystals synthesized at different temperatures for $16 \mathrm{~h}$ : (a) nanocubes at $150^{\circ} \mathrm{C}$ and (b) nanospheres at 180 ${ }^{\circ} \mathrm{C}$; (Nguyen et al. 2009a) TEM images and SAED patterns of the $\mathrm{SmVO}_{4}$ nanocrystals synthesized from a 1:1 mixture of $\mathrm{Sm}(\mathrm{OA})_{3}$ and $\mathrm{VO}_{4}(\mathrm{TOA})_{3}$ in toluene using various surfactants: (c,d) oleylamine, $17 \mathrm{~nm}$ nanospheres, (e,f) oleic acid, $17 \mathrm{~nm}$ nanohexagons, and (g) Schematic illustration for the shape control of the $\mathrm{SmVO}_{4}$ nanocrystals (Nguyen et al. 2009b). 
and amount of capping surfactant as well as the metal complex precursor concentration (Nguyen et al. 2009b) Figure 8c-f displays TEM images of the $\mathrm{SmVO}_{4}$ nanocrystals obtained using two different surfactants (e.g., oleylamine and oleic acid), and the corresponding SAED patterns. When only oleylamine was used, nanospheres with $\sim 17 \mathrm{~nm}$ in diameter were obtained (Figure $8 \mathrm{c}, \mathrm{d}$ ). However, using oleic acid as capping surfactant instead of oleylamine under the same synthesis conditions, hexagonal-like $\mathrm{SmVO}_{4}$ nanocrystals with no significant change in particle size $(\sim 17 \mathrm{~nm}$ in diameter) were formed (Figures $8 \mathrm{e}, \mathrm{f})$. The SAED results revealed that both the samples are indexed to a tetragonal $\mathrm{SmVO}_{4}$ single crystal. The selective-shape formation of the $\mathrm{SmVO}_{4}$ nanocrystals nanospheres and nanohexagonons can be resulted in the nonselective and selective absorption of oleylamine or oleic acid, respectively.

The effect of oleylamine (OM) and metal complex precursor concentrations on the growth of $\mathrm{SmVO}_{4}$ nanoparticles was also studied, as shown in Figure 9 (Nguyen et al. 2009b). In the absence of OM, only irregular nanocrysqtals with aggregated pearl-chain-like structures often formed. When the OM concentration increased from 0.025 to $0.060,0.129,0.230,0.034$, and $0.43 \mathrm{M}$, the particle size of $\mathrm{SmVO}_{4}$ nanoparticles decreased from $\sim 30$ to $3 \mathrm{~nm}$. The reason for this behaviour may be due to the high degree of surfactant protection and stabilization of nanocrystals with increasing the OM concentrations in the bulk reaction solution. The larger and irregular sizes of the nanocrystals at low OM concentrations as compared to those obtained at high OM concentrations may result in insufficient coverage to the nanocrystal surface and induce their aggregation. Furthermore, in all the cases, the spherical nanocrystals were produced. The formation of spherical NPs could be due to the nonselective surfactant character of oleylamine $(\mathrm{OM})$. On the other hands, it was found that the shape of $\mathrm{SmVO}_{4}$ nanocrystals elongated from $\sim 3 \mathrm{~nm}$ cores into $\sim 3 \mathrm{~nm} \times 200 \mathrm{~nm}$ wires as increasing the metal complex precursor concentrations from 0.065 to $0.130,0.195,0.260 \mathrm{M}$. These results reveal that the shape evolution from nanocores to nanowires can be controlled by increasing the precursor monomer concentration, which is strongly associated with the increase of chemical potential in the bulk solution as well as the dominant oriented attachment for the formation of nanowires (Nguyen et al. 2009b)

Due to their remarkable luminescence properties, Li's group(Liu and Li 2007) has also developed a general oleic acid-assisted hydrothermal method for the synthesis of a series of colloidal rare earth orthovanadate nanocrystals through the hydrothermal reaction of metal nitrate, $\mathrm{NaOH}, \mathrm{NH}_{4} \mathrm{VO}_{3}$, oleic acid, ethanol/water mixture. The morphologies of all products were mainly square sheetlike shape with average diameters of $\sim 20-40 \mathrm{~nm}$. The products were formed by capping of oleic acid to $\mathrm{Ln}^{3+}$ first, then oleic acid attached rare earth ion $\left(\mathrm{Ln}^{3+}\right)$ reacted with $\mathrm{VO}_{4}^{3-}$ to form $\mathrm{LnVO}_{4}$ nuclei at the water-oleic acid interface. This was followed by crystal growth until the nanocrystals were large enough to fall to the bottom of the vessel. Further, $\mathrm{Eu}^{3+}$-doped $\mathrm{LnVO}_{4}$ nanocrystals emitted intense red light. The author also used this route to synthesize colloidal uniform rare earth floride nanocrystals (Li, Peng and Li 2009, Wang et al. 2006). Lin et al. (Xu et al. 2010) synthesized and studied the luminescence properties of $\mathrm{Ln}^{3+}(\mathrm{Ln}=\mathrm{Eu}, \mathrm{Dy}, \mathrm{Sm}, \mathrm{Er})$-doped $\mathrm{YVO}_{4}$ nanocrystals via the trisodium citrate-assisted hydrothermal process. Haase et al (Sun et al. 2006c) also demonstrated an increase of visible emission intensity of $\mathrm{Er}^{3+}$-doped $\mathrm{YVO}_{4}$ nanocrystals due to photoadsorption and energy transfer of $\mathrm{Er}^{3+}$ ions to the host $\mathrm{YVO}_{4}$. An another general ultrasonic irradiation route for the lanthanide orthovanadate $\mathrm{LnVO}_{4}$ ( $\left.\mathrm{Ln}=\mathrm{La}-\mathrm{Lu}\right)$ nanocrystals from the aqueous solution of $\mathrm{Ln}\left(\mathrm{NO}_{3}\right)_{3}$ and $\mathrm{NH}_{4} \mathrm{VO}_{3}$ without any surfactant were also reported by $\mathrm{Lin}$ et al. (Yu et al. 2008). The resulting $\mathrm{LnVO}_{4}$ nanocrystals had 


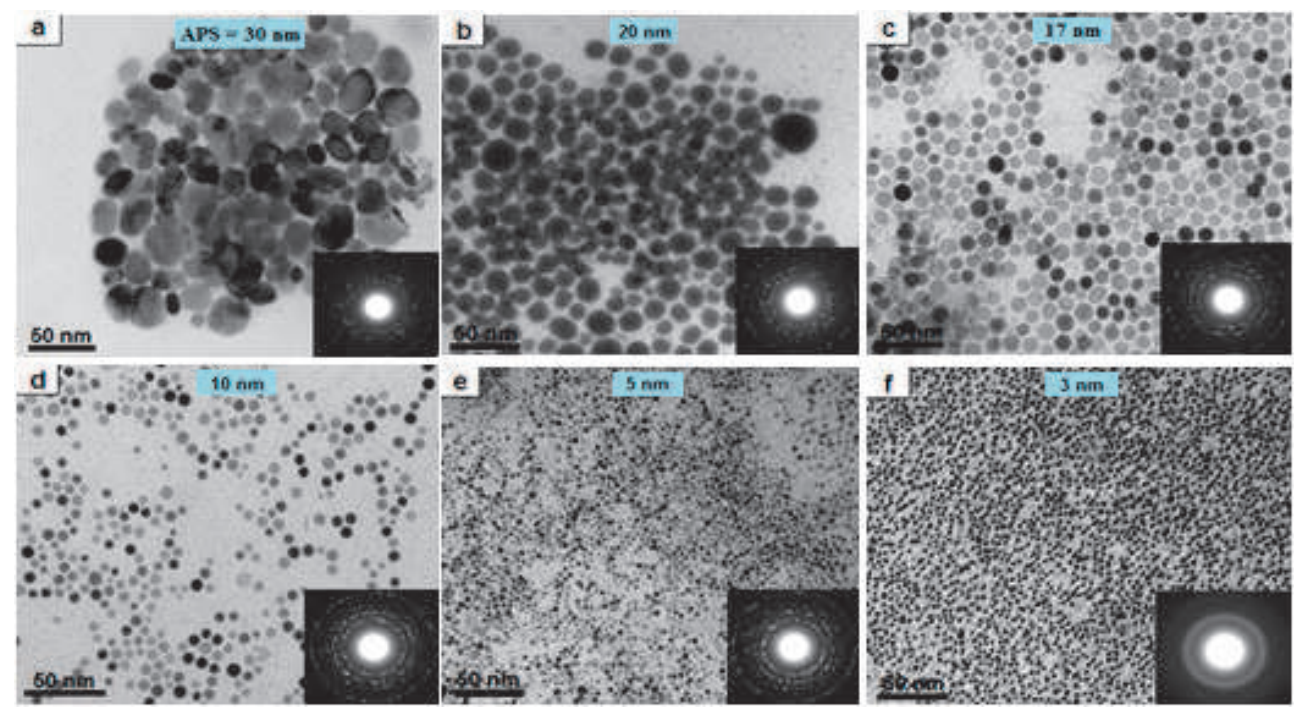

Fig. 9. Effect of the oleylamine concentration in the bulk solution on the particle size. TEM images and corresponding inset SAED patterns of the $\mathrm{SmVO}_{4}$ nanocrystals synthesized using the different molar ratios of oleylamine:precursor $(O M: P)$ : (a) $O M: P=0.8,30 \mathrm{~nm}$ roundlike nanocrystals, (b) $O M: P=2,20 \mathrm{~nm}$ nanospheres, (c) $O M: P=4,17 \mathrm{~nm}$ nanospheres, (d) $O M: P=8,10 \mathrm{~nm}$ nanospheres, (e) $O M: P=12,5 \mathrm{~nm}$ nanospheres, and (f) $O M: P=17,3$ $\mathrm{nm}$ nanocores. Average particle size $=$ APS (Nguyen et al. 2009b).

spindle-like shape with the equatorial diameter of 30-70 nm and the length of 100-200 nm, which were the aggregates of small particles of 10-20 nm. Furthermore, the $\mathrm{Eu}^{3+}$ and $\mathrm{Dy}^{3+}-$ doped $\mathrm{LnVO}_{4}(\mathrm{Ln}=\mathrm{La}, \mathrm{Gd}, \mathrm{Lu})$ samples showed the characteristic dominant emissions of $\mathrm{Eu}^{3+}$ at $613 \mathrm{~nm}$ and $\mathrm{Dy}^{3+}$ at $572 \mathrm{~nm}$, respectively, as a result of an energy transfer from $\mathrm{VO}_{4}{ }^{3-}$ to $\mathrm{Eu}^{3+}$ or $\mathrm{Dy}^{3+}$.

Manganese tungstate $\left(\mathrm{MnWO}_{4}\right)$ is one of the most promising mixed metal oxide nanomaterials, which exhibits high sensitivity to humidity change and unique magnetic property (Qu, Wlodarski and Meyer 2000, Arkenbout et al. 2006, Heyer and et al. 2006). Hence, it has attracted considerable research interest for potential applications such as photocatalysts, humidity sensors, optical fibers, photoluminescence and scintillator materials (Xing et al. 2008, Qu et al. 2000, Bharati, Singh and Wanklyn 1982). Several efforts have been devoted to the synthesis of $\mathrm{MnWO}_{4}$ nanoparticles and especially focused on the shape and dimensional control (Zhou et al. 2008b, Zhang et al. 2008b). We recently developed a new approach for the aqueous-phase "one-step" synthesis of uniform singlecrystalline $\mathrm{MnWO}_{4}$ nanoparticles with controlled shape and the self-assembled mesocrystal microspheres/microapples with high yield using $\mathrm{Mn}\left(\mathrm{NO}_{3}\right)_{2}$ and $\mathrm{Na}_{2} \mathrm{WO}_{4}$ as precursors and bifunctional amino acid biomolecules as capping agent. $\mathrm{MnWO}_{4}$ nuclei were early formed by the combination of $\mathrm{Mn}^{2+}$ cations and $\mathrm{WO}_{4}{ }^{2-}$ anions and then grew into nanocrystals (Nguyen et al. 2011b). The nanoparticle products were capped by the amino head groups of 6-aminohexanoic acid (AHA) biomolecules and their surface become hydrophilic owing to other end of the uncoordinated carboxylic groups. Because of the hydrophilic surface character, the final products can be suspended in water medium. 


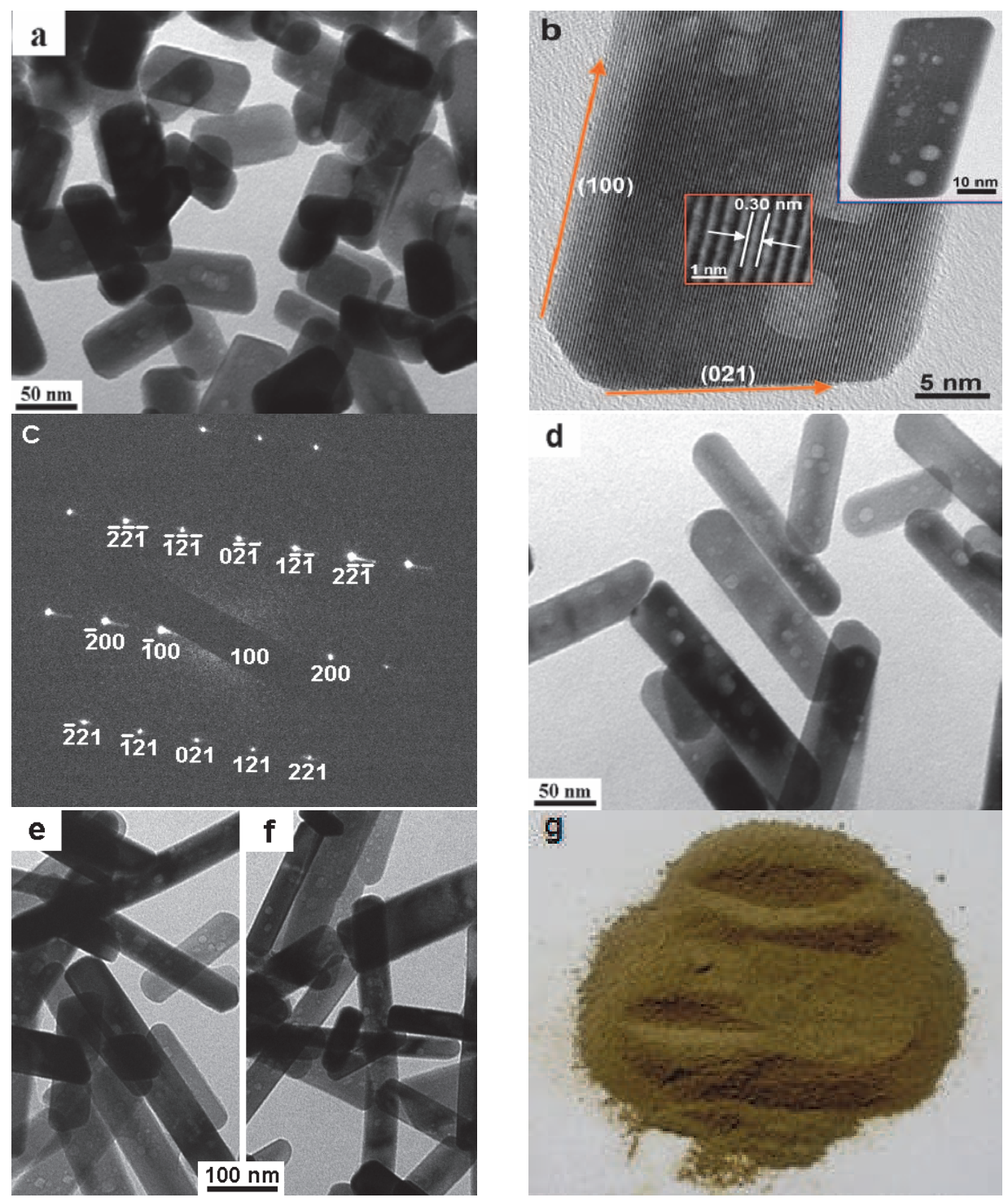

Fig. 10. TEM images of the $\mathrm{MnWO}_{4}$ nanocrystals synthesized from an aqueous solution of $0.015 \mathrm{M} \mathrm{Mn}\left(\mathrm{NO}_{3}\right)_{2}$ and $0.015 \mathrm{M} \mathrm{Na}_{2} \mathrm{WO}_{4}, \mathrm{pH}=9,180{ }^{\circ} \mathrm{C}$ for $20 \mathrm{~h}$, using the different 6aminohexanoic acid/ $(\mathrm{Mn}+\mathrm{W})$ molar ratios $(A H A / P)$ : (a) $25 \mathrm{~nm} \times 50 \mathrm{~nm}$ nanobars, $A H A / P=$ 2:1; (b) HRTEM image of an individual nanobar; (c) SAED pattern of a single bar taking along [100] zone axis; (d) $25 \mathrm{~nm} \times 100 \mathrm{~nm}$ nanorods, $A H A / P=10: 1$; (e) $25 \mathrm{~nm} \times 150 \mathrm{~nm}$ nanorods, $A H A / P=20: 1$; (f) $25 \mathrm{~nm} \times 150 \mathrm{~nm}$ nanorods, $A H A / P=30: 1$; (g) one photo of $\sim 16$ grams of 6-aminohexanoic acid-capped $\mathrm{MnWO}_{4}$ nanobar powders synthesized using $\left[\mathrm{Mn}^{2+}\right]$ $=\left[\mathrm{WO}_{4}{ }^{2-}\right]$ of $0.122 \mathrm{M}, 0.243 \mathrm{M}$ of AHA, $\mathrm{pH}=9,180{ }^{\circ} \mathrm{C}$ for $20 \mathrm{~h}$, in a $700 \mathrm{~mL}$-sized autoclave (Nguyen et al. 2011b). 
The experimental results revealed that the shape elongation of $\mathrm{MnWO}_{4}$ nanoparticles is affected by capping 6-aminohexanoic acid concentration in the aqueous solution. Figure 10 shows TEM/HRTEM images of the $\mathrm{MnWO}_{4}$ nanoparticles synthesized using AHA concentration ranging from 0.031 to $0.305,0.610,0.915 \mathrm{M}$, corresponding to the AHA/ $(\mathrm{Mn}+\mathrm{W})$ molar ratio ranging from 2:1 to 10:1, 20:1, 30:1 (Nguyen et al. 2011b). The elongation of nanoparticles from $25 \mathrm{~nm} \times 50 \mathrm{~nm}$-sized nanobar to $25 \mathrm{~nm} \times 150 \mathrm{~nm}$-sized nanorods with increasing 6-aminohexanoic acid (AHA) concentration from 0.031 to $0.610 \mathrm{M}$ was clearly observed. The high-resolution TEM results (Figure 10b) of a $\mathrm{MnWO}_{4}$ nanobar suggest that the nanobar is single crystal with an interplanar spacing of $0.30 \mathrm{~nm}$, which corresponds to the separation between the (200) lattice planes of monoclinic $\mathrm{MnWO}_{4}$. The side surfaces of the nanobar were bounded by (100) plane and the ends of the nanobar were enclosed by the (021) plane. The (100) planes are oriented parallel to the nanobars' growth axis, suggesting that the growth direction of the single-crystalline nanobar occurs preferentially along the [100] direction (c-axis), in good agreement with the SAED data (Figure 10c). The shape evolution could suggest that the (021) faces of nanocrystals could be selectively adsorbed and stabilized by AHA molecules, while the (100) faces were uncovered. The crystal grew anisotropically along the [100] direction due to their higher surface energies resulting in the nanorod product. Because AHA adsorbed onto only specific (021) faces, the nanorods with high aspect ratios produced at high AHA concentration could be due to the oriented attachment of nanocrystals predominantly during the synthesis.

In this synthesis approach, water is adopted as the continuous solution phase and inorganic salts were used as starting materials. Due to the high solubility of the salts in aqueous solution, it is applicable to synthesize the nanoparticles in scale up by using the high precursor monomer concentrations. This aqueous-based method is thus a promising way in the academic laboratory as well as can be expanded to the industrial scale in a simple way. In fact, we obtained as much as 16 grams of $\sim 25 \mathrm{~nm} \times 50 \mathrm{~nm} \mathrm{MnWO}_{4}$ nanobars per single run in a $700 \mathrm{~mL}$-sized autoclave when the high precursor concentration of $0.122 \mathrm{M}$ was used (Figure 10g) (Nguyen et al. 2011b).

The self-assembly of tailored nanobuilding units into three-dimensional (3D) mixed metal oxide microarchitectures has recently received considerable interest. Many novel and fascinating properties of these materials and useful applications are predicted depending not only on the complex morphology but also on the order degree of single-crystalline nanoparticles in microarchitectures. Sacrificial organic surfactants can act as structuredirecting agents or soft templates and are widely used to design nano/microstructures with peculiar morphologies. The amino acid molecules are considered as fine assemblied agents. In this work, we also found that the formation of self-assemblied $\mathrm{MnWO}_{4} 3 \mathrm{D}$ hierarchical microspheres from nanobars is favorable at relatively low precursor concentration $(0.0076$ M) of $\mathrm{Mn}^{2+}$ cation and $\mathrm{WO}_{4}^{2-}$ anion precursors in the initial synthesis solution in the presence of 6-aminohexanoic acid surfactant (Nguyen et al. 2011b) SEM/TEM images in Figure 11A shows that self-assemblied products is quite monodisperse microspheres with two size populations, $3-5 \mu \mathrm{m}$ and $8-16 \mu \mathrm{m}$. The peripheral surface of the microsphere is rough and each microsphere is composed of numerous disordered nanobars suggesting that the formation of microspheres is likely driven by the interaction of inter-nanobars.

The FTIR results clarified that the assembly mechanism of the formed microspheres caused by generating the peptide chains in bulk solution during synthesis. Only the amino $\left(-\mathrm{NH}_{2}\right)$ group of AHA molecules capped on the surface of $\mathrm{MnWO}_{4}$ nanoparticles and the free carboxylic $(-\mathrm{COOH})$ terminus was oriented outward. The polypeptide chains were formed 


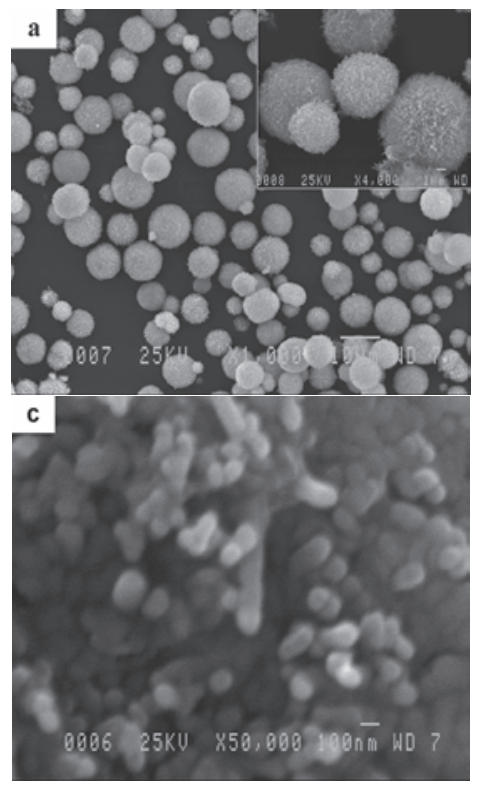

6-aminohexanoic acidcapped $\mathrm{MnWO}_{4}$ nanorods

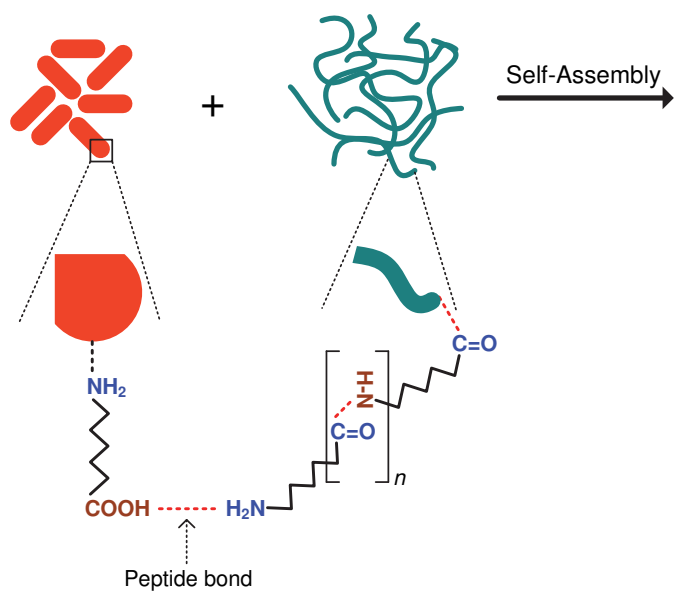

(A)
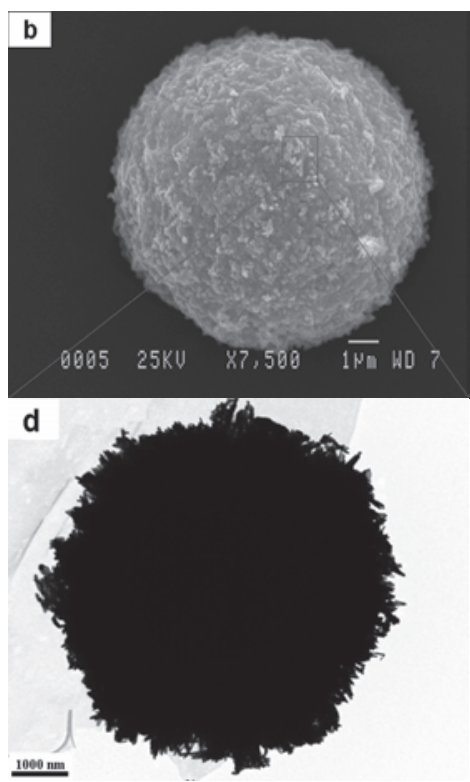

(B)

Polypeptide-stabilized microspheres

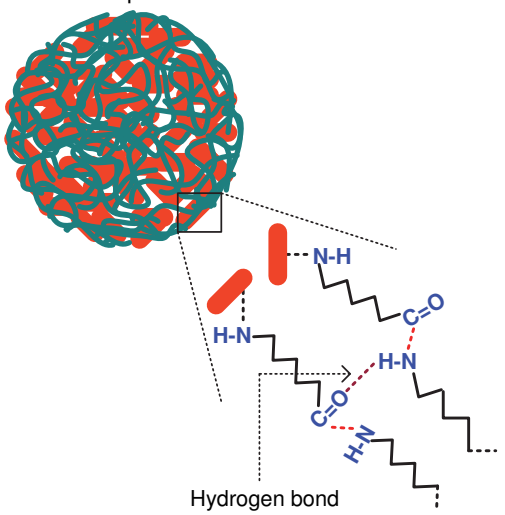

Fig. 11. (A) Different-magnification SEM (a-c) and TEM (d,e) images, inset SAED pattern of the self-assembled $\mathrm{MnWO}_{4}$ hierarchical microspheres synthesized using $\left[\mathrm{Mn}^{2+}\right]=\left[\mathrm{WO}_{4}{ }^{2-}\right]$ of $0.0076 \mathrm{M}, 0.0305 \mathrm{M}$ of AHA, $\mathrm{pH}=9,180{ }^{\circ} \mathrm{C}$ for $20 \mathrm{~h}$. (f) $\mathrm{SEM}$ image of the broken $\mathrm{MnWO}_{4}$ microspheres achieving ultrasonic treatment. (B) A possible proposed mechanism for the construction of the 3D hierarchical $\mathrm{MnWO}_{4}$ microspheres from self-assembly of nanobars using low precursor monomer concentration (0.0076 M) (Nguyen et al. 2011b). 
through the interaction between this uncoordinated carboxylic group on the nanobar surface and the amino group of residual 6-aminohexanoic acid in aqueous solution. The selfassembly of the peptide structure led to produce the assembled $\mathrm{MnWO}_{4}$ microspheres. Further, the microsphere morphology can thus be controlled by adjusting the concentration of the peptide, that is, the concentration of 6-aminohexanoic acid (Nguyen et al. 2011b).

This suggests that with a low concentration of $\mathrm{Mn}^{2+}$ and $\mathrm{WO}_{4}{ }^{2-}$ precursors $(0.0076 \mathrm{M}$, $(\mathrm{Mn}+\mathrm{W}) /$ AHA molar ratio of 0.25:1) and a low nuclei of $\mathrm{MnWO}_{4}$ was formed and a small amount of $\mathrm{MnWO}_{4}$ nanoparticles was produced. Due to the relatively high surfactant concentration $(0.031 \mathrm{M})$, an excess amount of free 6-aminohexanoic acid exists in the aqueous synthesis solution, the dipeptide/polypeptide process of both $-\mathrm{NH}_{2}$ and $-\mathrm{COOH}$ groups of free 6-aminohexanoic acid occurred on the basis of nucleophile mechanism, resulting in the formation of polypeptide chains. Because only small amount of $\mathrm{MnWO}_{4}$ nanobars was yielded in bulk solution and because of the high AHA concentration, the peptide reaction continued and the reaction between the amino groups of the formed amino acid sequence of protein and the uncoordinated carboxylic groups on the nanoparticle surface to generate the polypeptide-stabilized $\mathrm{MnWO}_{4}$ nanobars. Subsequently, highly oriented backbone-backbone intermolecular hydrogen-bonding interactions of numerous amphiphilic polypeptide chains via either antiparallel or parallel arrangements were proceeded to spontaneous-assemble into polypeptide-stabilized $\mathrm{MnWO}_{4}$ microspheres. These interactions are thermodynamically favorable due to the reduction of the particle surface energy when the interface is eliminated. On the contrary, a large amount of monodisperse nanobars was yielded using a higher precursor monomer concentration $(0.015 \mathrm{M},(\mathrm{Mn}+\mathrm{W}) / \mathrm{AHA}$ molar ratio of $0.48: 1)$ with a faster nucleation of $\mathrm{MnWO}_{4}$. The excess amount of free 6-aminohexanoic acid in synthesis solution decreased strongly because they were consumed more for the capping on nanobar surface. A possible proposed mechanism of the "one-step" formation of self-assemblied $\mathrm{MnWO}_{4}$ hierarchical microspheres is illustrated in Figure 11B. The photoluminescence results indicated that the PL emission intensity of the $\mathrm{MnWO}_{4}$ nanobars is higher than that of the $\mathrm{MnWO}_{4}$ microspheres indicating the decrease in the luminescence efficiency of the microspheres due to nanobars inside of microspheres (Nguyen et al. 2011b).

$\mathrm{MnWO}_{4}$ nanomaterials have been synthesized and revealed several morphologies such as flower-like clusters, nanowires, nanoplates, and nanorods (Zhang et al. 2007b, Zhou et al. 2008b, Thongtem, Wannapop and Thongtem 2009, Chen et al. 2003, Zhou et al. 2008a). Additionally, the kinetic control of $\mathrm{MnWO}_{4}$ nanoparticles grown for tailored structural properties were studied by Li et al. (Tong et al. 2010). To extend for these tungstates, Wong et al. (Zhang et al. 2008a) developed a room-temperature template-directed method for the synthesis of single-crystalline alkaline-earth-metal tungstate $\mathrm{AWO}_{4}(\mathrm{~A}=\mathrm{Ca}, \mathrm{Sr}, \mathrm{Ba})$ nanorods with unique optoelectronic properties. The $2 \mathrm{D}$ self-organization of $\mathrm{BaWO}_{4}$ nanorods at the water-air interface was performed on the basis of a Langmuir-Blodgett technique (Kim et al. 2001). By using the catanionic reversed micelle templating method, single-crystalline $\mathrm{BaWO}_{4}$ nanorods with high-aspect-ratio were produced (Shi et al. 2003b). The penniform $\mathrm{BaWO}_{4}$ nanostructures could be generated in reverse micellar system containing double-hydrophilic block copolymers (Shi et al. 2003a). Also used a microemulsion with solvothermal association, the $\mathrm{SrWO}_{4}$ nanorods of $100 \mathrm{~nm}$ in diameter and 500-1500 $\mathrm{nm}$ in length were yielded (Sun et al. 2006b). In the solution-based selfassembly process, through properly employing organic additives to the reaction system, the growth of inorganic nanocrystals can be rationally directed to obtain products with 
desirable morphologies and/or hierarchical structures. For example, Cascales et al. (Esteban-Betegón, Zaldo and Cascales 2010) have produced the tetragonal scheelite-phase $\mathrm{Yb}^{3+}$-doped $\mathrm{NaGd}\left(\mathrm{WO}_{4}\right)_{2}$ micro/nanostructures with preserved photoluminescence properties from hydrothermal preparations using metal nitrate and chloride reagents. Shen et al. (Liu et al. 2004) synthesized the single crystalline $\mathrm{ZnWO}_{4}$ nanorods via the direct aggregation of the amorphous nanoparticles, and promote the crystallization process of the amorphous $\mathrm{ZnWO}_{4}$ particles derived from the precipitation reaction in a nanorod/amorphous nanoparticle coexisting system. Yu et al. (Zhang et al. 2007c) have used the refluxing method to fabricate the uniform core-shell heterostructured $\mathrm{ZnWO}_{4} @ \mathrm{MWO}_{4}(\mathrm{M}=\mathrm{Mn}, \mathrm{Fe})$ nanorods with optical and antiferromagnetic characters. The direct crystallization of the $\mathrm{MWO}_{4}$ nuclei occurred on the backbone of $\mathrm{ZnWO}_{4}$ nanorods without surfactant. The formation of the hybrid $\mathrm{ZnWO}_{4} @ \mathrm{MWO}_{4}(\mathrm{M}=\mathrm{Mn}, \mathrm{Fe})$ nanorods based on the oriented aggregation. The shell thickness of $\mathrm{MWO}_{4}$ could be tuned by changing the molar ratio of these raw materials.

Many other research groups have also used the solvo-hydrothemal method to synthesize the mixed metal oxide nanocrystals. For example, Yu et al. (Zhou et al. 2009) reported an effective ethylene glycol (EG)-assisted solvothermal method to synthesize hierarchical $\mathrm{FeWO}_{4}$ microcrystals using $\mathrm{FeCl}_{3} \cdot 6 \mathrm{H}_{2} \mathrm{O}$ and $\mathrm{Na}_{2} \mathrm{WO}_{4} \cdot 2 \mathrm{H}_{2} \mathrm{O}$ as precursors. It was found that the organic solvent EG played a critical role as both a reducing agent and a structuredirecting agent in driving such architectures assembled by oriented attachment of primary nanoparticles. Moreover, a certain amount of $\mathrm{CH}_{3} \mathrm{COONa}$ was necessary for the formation of such unique platelike $\mathrm{FeWO}_{4}$ microcrystals. The photocatalytic property of as-synthesized hierarchical $\mathrm{FeWO}_{4}$ microcrystals was also studied, which shows excellent photocatalytic activity for the degradation of rhodamine B. Cascales et al. (Esteban-Betegón et al. 2010) has produced the tetragonal scheelite-phase $\mathrm{Yb}^{3+}$-doped $\mathrm{NaGd}\left(\mathrm{WO}_{4}\right)_{2}$ micro/nanostructures with preserved photoluminescence properties from hydrothermal preparations using metal nitrate and chloride reagents. The Li's group has successfully prepared a novel hollow $\mathrm{CeO}_{2-}$ $\mathrm{ZrO}_{2}$ nanocages with controlled shapes, sizes, and compositions by adding zirconium(IV) into the glycol solution containing $\mathrm{CeO}_{2}$ nanospheres under solvothermal treatment (Liang et al. 2008). The formation of cage-structured $\mathrm{CeO}_{2}-\mathrm{ZrO}_{2}$ nanomaterials was explained by the Kirkendall effect. When $\mathrm{Zr}^{4+}$ ions were added into the system, they readily doped into ceria to form a solid solution of the type $\mathrm{Ce}_{1-x} \mathrm{Zr}_{x} \mathrm{O}_{2}$; meanwhile, the diffusion rate of the special secondary nanostructure of the resulting clusters was obviously much faster than that of the single-element nanostructure, leading to the formation of hollow nanostructures of the $\mathrm{Ce}_{1-x} \mathrm{Zr}_{x} \mathrm{O}_{2}$ type. $\mathrm{Yu}$ and coworkers(Gu et al. 2003) noted that hydrothermal heating at $180{ }^{\circ} \mathrm{C}$ of an ammoniacal $\mathrm{FeCl}_{2}$ solution containing metallic $\mathrm{Zn}$ leads to the formation of octahedrally-shaped $\mathrm{ZnFe}_{2} \mathrm{O}_{4}$ nanoparticles with an average size of $300 \mathrm{~nm}$. Using liquidsolid-solution approach, $\mathrm{Li}$ et al. has been successfully employed multicomponent nanocrystals not only with mixed metal oxide nanocrystals $\left(\mathrm{LnVO}_{4}\right.$ and $\left.\mathrm{LnPO}_{4}\right)$ but also with lanthanide doped $\mathrm{NaYF}_{4}$ nanocrystals (Liu and Li 2007).

Related progress using this two-phase approach was also applied for the synthesis of a variety of mixed inorganic nanomaterials under solvo/hydrothermal treatment. A modified two-phase approach for the synthesis of the CdS nanocrystals at the water/toluene interface was carried out by mixing cadimium myristate toluene solution and thioure aqueous solution (Wang et al. 2005a). Additionally, these authors used a seeding-growth technique to change the CdS nanocrystal sizes. They also synthesized the CdSe and CdSe/CdS core/shell 
nanocrystals using selenourea as a selenium precursor by this two-phase approach. The CdSe/CdS core/shell nanocrystals exhibited quantum yields up to $60-80 \%$, the photoluminescence of these nanocrystals can be clearly observed even without UV lamp irradiation (Pan et al. 2005a). By an alternant growth technique, the authors also synthesized two multi-shell nanocrystals of CdS/CdSe/CdS/CdSe/CdS and CdSe/CdS/CdSe/CdS/CdSe/CdS nanocrystals (Pan et al. 2006). In all cases, the obtained products had the narrow size distributions due to the use of low reaction precursors. Xu et al. (Wang et al. 2009) have recently achieved rare-earth doped $\mathrm{NaYF}_{4}$ up conversion fluorescent nanocrystals using water/ethanol/rare-earth stearate/oleic acid system. Kaskel et al. (Du et al. 2007) also used this two phase solvothermal method to synthesize of $\mathrm{BaTiO}_{3}$ nanocrystals using mixed titanium(IV)- $n$-butoxide and barium acetate precursors.
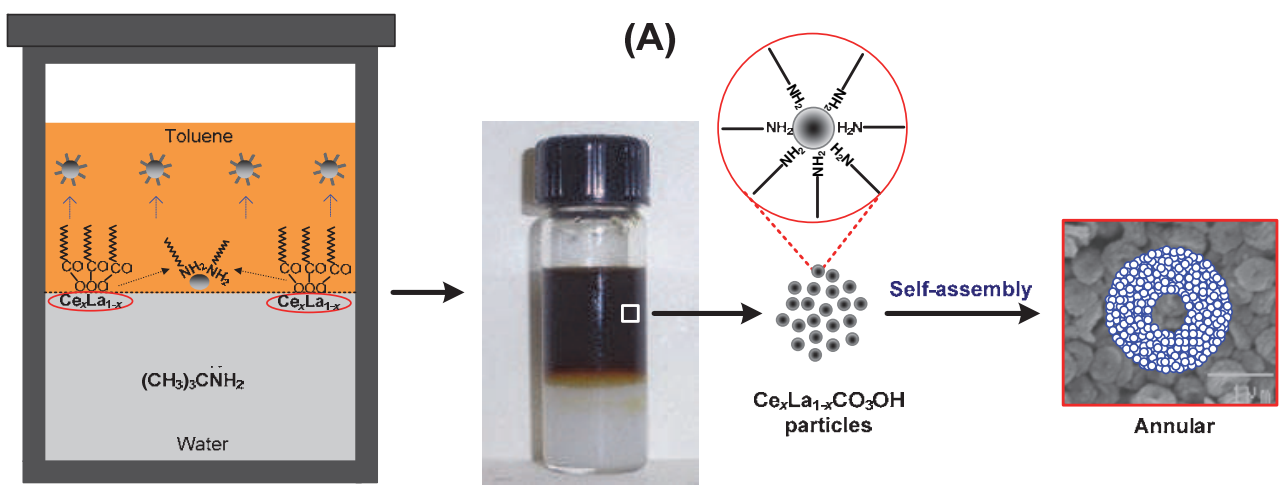

(B)
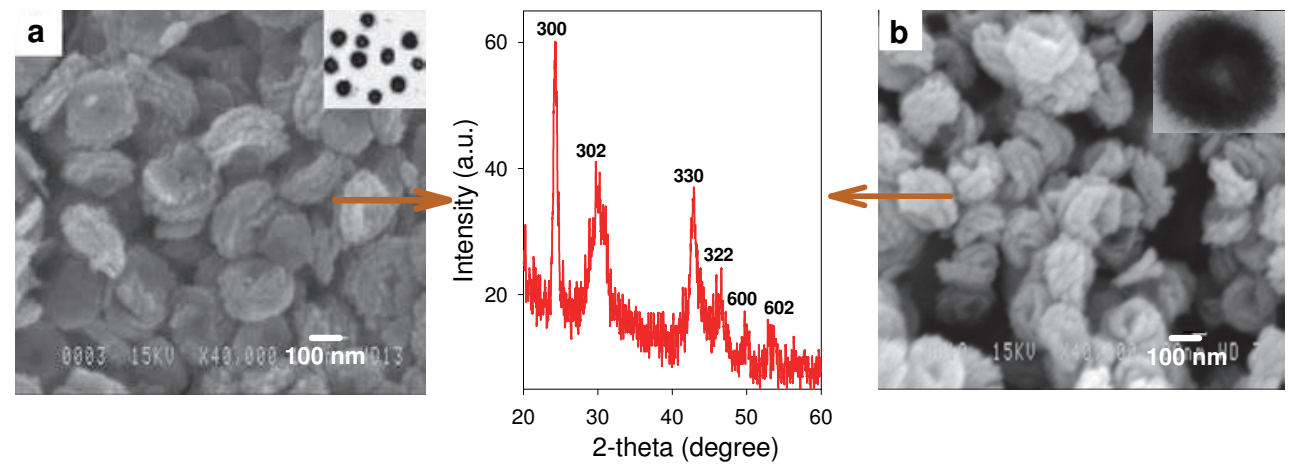

Fig. 12. (A) Two-phase protocol for the synthesis of the undoped and cerium doped $\mathrm{LaCO}_{3} \mathrm{OH}$ annular-shaped nanoarchitectures; (B) SEM/TEM images of undoped $\mathrm{LaCO}_{3} \mathrm{OH}$ (a) and cerium doped $\mathrm{LaCO}_{3} \mathrm{OH}$ (b) samples having the same pure hexagonal-phase and annular shape (Nguyen, Dinh and Do 2011a).

Our group recently reported a modified two-phase method for the synthesis of alkyl chaincapped metal particles (e.g., $\mathrm{Cu}$ and $\mathrm{Au}$ ) and metal oxide nanoparticles $\left(\mathrm{TiO}_{2}\right.$ and $\left.\mathrm{ZrO}_{2}\right)$, followed by their cooperative assemblage into unusual hybrid metal/metal oxide 
nanocrystal mesostructured materials (Mrabet, Zahedi-Niaki and Do 2008). The catalytic activity of these hybrid products for the $\mathrm{CO}$ oxidation was also employed. Indeed, these hybrid metal/metal oxide nanocatalysts exhibited high surface areas, narrow pore size distributions, and exceptional catalytic properties in the oxidation of $\mathrm{CO}$, even surpassing the performance of commercial noble metal catalysts.

Cerium doped lanthanum(III) carbonate hydroxide $\left(\mathrm{Ce}_{x} \mathrm{La}_{1-x} \mathrm{CO}_{3} \mathrm{OH}\right)$ has drawn a great deal of interest as a promising luminescent material because of the empty $4 \mathrm{f}$ shell of $\mathrm{La}^{3+}$ and the lack of electronic f-f transitions (Binnemans 2009, Bünzli 2010). This is mainly due to their unique electronic and optical properties arising from the $4 \mathrm{f}$ electrons of cerium (Su et al. 2009). Cerium incorporation in the $\mathrm{LaCO}_{3} \mathrm{OH}$ structure can improve the reactive performance, because of the generation of crystalline defects (Meiser, Cortez and Caruso 2004, Ding et al. 2001). Thus its physical and chemical properties can be controlled by atomic-scale precision, and this type of materials can be tailored to possess specific properties. These make these cerium doped $\mathrm{LaCO}_{3} \mathrm{OH}$ materials to have potential applications in catalysis,(Sun et al. 2006a) high-quality phosphors,(Mai et al. 2006) upconversion materials,(Auzel 2003) oxygen-ion conducting electrolytes (Etsell and Flengas 1970).

We recently reported the fabrication of undoped and cerium doped $\mathrm{LaCO}_{3} \mathrm{OH}$ annularshaped nanoarchitectures with high specific surface area via the thermolysis of the binary source precursor, $\mathrm{Ce}_{x} \mathrm{La}_{1-x}$ (oleate) $)_{3}$ complex $(x=0-20 \mathrm{~mol} \%)$, in water-toluene system containing tert-butylamine/oleylamine (Nguyen et al. 2011a). The two-phase synthetic procedure consists of two steps, as shown in Figure 12A: (i) the preparation of $\mathrm{Ce}_{x} \mathrm{La}_{1-}$ $x$ (oleate $)_{3}$ complex from the reaction between respective lanthanide nitrate and potassium oleate in a water-toluene solution; (ii) the formation of mesoporous $\mathrm{Ce}_{x} \mathrm{La}_{1-x} \mathrm{CO}_{3} \mathrm{OH}$ annularshaped nanoarchitectures in an autoclave containing a water-toluene mixture composed of $\mathrm{Ce}_{x} \mathrm{La}_{1-x}$ (oleate) $)_{3} /$ tert-butylamine/oleylamine at $180{ }^{\circ} \mathrm{C}$ for $24 \mathrm{~h}$. The solid-solution ceriumlanthanum oxide particles were produced from the decarbonation and dehydration of $\mathrm{Ce}_{x} \mathrm{La}_{1-x} \mathrm{CO}_{3} \mathrm{OH}$ upon annealing. The $\mathrm{Ce}_{x} \mathrm{La}_{1-x} \mathrm{CO}_{3} \mathrm{OH}$ nanoarchitectures were capped by the amine groups of oleylamine molecules, the exposed hydrophobic alkyl groups were wellimmersed in toluene, and guaranted the good dispersibility of the product in toluene phase. The XRD and SEM/TEM results (Figure 12B) revealed that the formed product without cerium doping exhibited the pure hexagonal-phase $\mathrm{LaCO}_{3} \mathrm{OH}$ structure with annular shape (Nguyen et al. 2011a). The monodisperse $\mathrm{LaCO}_{3} \mathrm{OH}$ annular-shaped nanoarchitectures revealed rough surface, narrow size distribution, average particle diameter of $<400 \mathrm{~nm}$, high specific surface area $\left(\sim 100 \mathrm{~m}^{2} \cdot \mathrm{g}^{-1}\right)$, and are composed of numerous small 3-5 $\mathrm{nm}$ particle assemblies. The phase structure and morphology of $\mathrm{Ce}_{x} \mathrm{La}_{1-x} \mathrm{CO}_{3} \mathrm{OH}$ is unchanged as cerium doping concentration ranging from 5 , to $10,15,20 \mathrm{~mol} \%$. This suggested that cerium ions tend to incorporate into the $\mathrm{LaCO}_{3} \mathrm{OH}$ lattice leading to a homogeneous $\mathrm{Ce}_{x} \mathrm{La}_{1-x} \mathrm{CO}_{3} \mathrm{OH}$ structure. No segregation of cerium species on the surface of the annular-shaped nanoarchitecture was observed, even up to $20 \mathrm{~mol} \%$ of cerium. This can be explained by) no significant difference in ionic radii of $\mathrm{Ce}^{3+}(1.150 \AA)$ and $\mathrm{La}^{3+}(1.172 \AA)$, which allows the replacement of $\mathrm{La}^{3+}$ by trivalent $\mathrm{Ce}^{3+}$ ions in $\mathrm{LaCO}_{3} \mathrm{OH}$. In contrast, by only $5.0 \mathrm{~mol} \%$ copper in the $\mathrm{LaCO}_{3} \mathrm{OH}$ structure, a separate phase: hexagonal $\mathrm{LaCO}_{3} \mathrm{OH}$, monoclinic $\mathrm{CuO}$, and cubic $\mathrm{Cu}_{2} \mathrm{O}$ phases was observed by its XRD pattern. Because the radius of $\mathrm{La}^{3+}$ ion is much larger than that of $\mathrm{Cu}^{+}$ion $\left(r\left(\mathrm{La}^{3+}\right)=1.172 \AA, r\left(\mathrm{Cu}^{2+}\right)=0.87 \AA, r\left(\mathrm{Cu}^{+}\right)=0.91 \AA\right)$, The copper ions cannot enter the lattice of $\mathrm{LaCO}_{3} \mathrm{OH}$ by occupying the $\mathrm{La}^{3+}$ ion sites (Nguyen et al. 2011a). 
The photoluminescence (PL) emission spectra (Figure 13) of the colloidal $\mathrm{Ce}_{x} \mathrm{La}_{1-x} \mathrm{CO}_{3} \mathrm{OH}$ nanoarchitectures with various doping levels $(x=0-20 \mathrm{~mol} \%)$ in toluene were recorded on exciting at $360 \mathrm{~nm}$ (Nguyen et al. 2011a). Using the same particle concentrations, the colloidal solutions of these $\mathrm{Ce}_{x} \mathrm{La}_{1-x} \mathrm{CO}_{3} \mathrm{OH}$ samples show the same spectral peak positions at $424,448,486,529,560 \mathrm{~nm}$, which can be attributed to the charge-transfer transition in $\mathrm{Ce}_{x} \mathrm{La}_{1-x} \mathrm{CO}_{3} \mathrm{OH}$ structure. The broad backgrounds of the luminescence spectra of these doped samples can be due to the self-assembly of small particles (3-5 $\mathrm{nm}$ ) for the formation of the aggregated $\mathrm{Ce}_{x} \mathrm{La}_{1-x} \mathrm{CO}_{3} \mathrm{OH}$ structure with annular shape. However, the effect of variation in emission can be correlated to the cerium doping concentration. The intensity was found to increase with increase in cerium doping level. The emission intensity of $\mathrm{Ce}_{x} \mathrm{La}_{1-x} \mathrm{CO}_{3} \mathrm{OH}$ sample increases with increase in cerium concentration to $20 \mathrm{~mol} \%$ and then exhibits a gradual decrease upon further increase in cerium doping content. The initial increase in emission intensity can be associated with the increase in relative concentration of the defects in the crystal structure. The subsequent decrease in emission intensity can be primarily attributed to the increase in particle size of the formed $\mathrm{Ce}$ doped $\mathrm{LaCO}_{3} \mathrm{OH}$ heterogeneous structure.

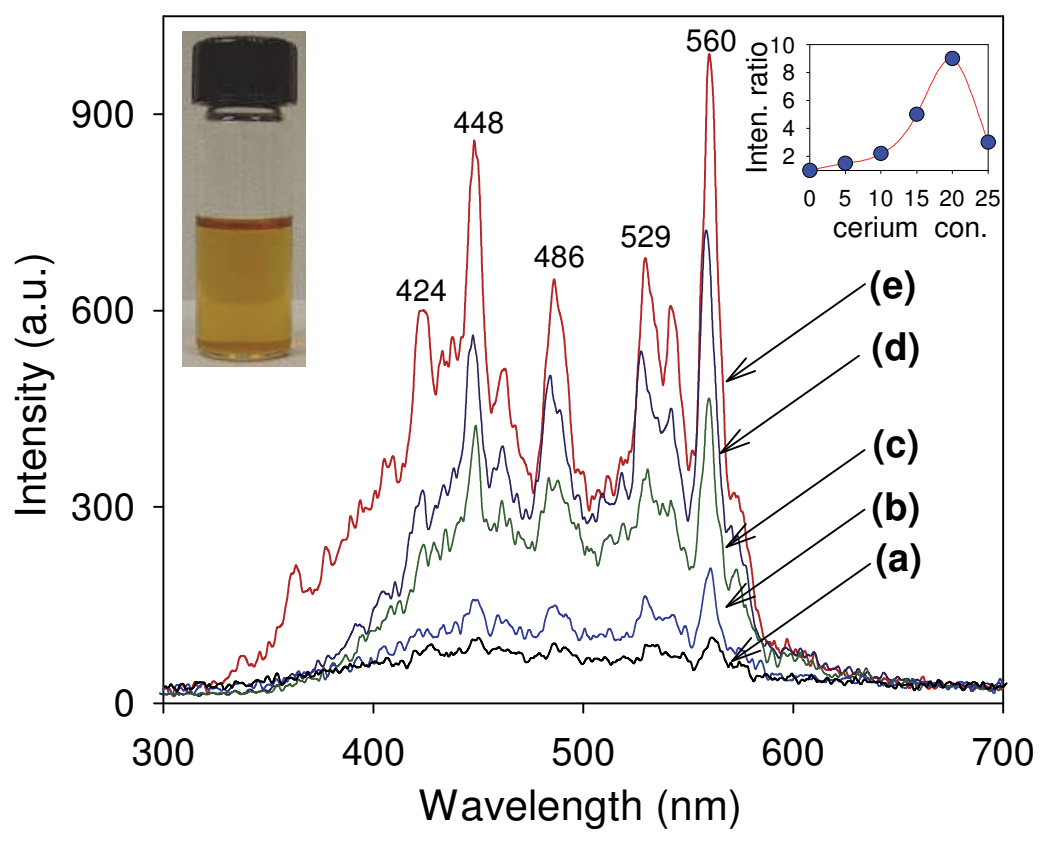

Fig. 13. Photoluminescence emission spectra (under excitation at $360 \mathrm{~nm}$ ) of the assynthesized $\mathrm{Ce}_{x} \mathrm{La}_{1-x} \mathrm{CO}_{3} \mathrm{OH}$ nanoannular samples with various doping levels (mol\%): (a) $x$ $=0$; (b) $x=5$; (c) $x=10$; (d) $x=15$; (e) $x=20$. Inset: one photo of transparent toluene solution containing colloidal $10 \mathrm{~mol} \%$ cerium doped $\mathrm{LaCO}_{3} \mathrm{OH}$ nanoannulars and the relationship between the cerium concentration and the PL intensity ratio (Nguyen et al. 2011a).

Xie et al. (Xie et al. 2009) fabricated the 1D layer-by-layer hexagonal-phased $\mathrm{La}(\mathrm{OH}) \mathrm{CO}_{3}$ hierarchical nanomaterials with a diameter of $\sim 700 \mathrm{~nm}$ and lengths in the range of $6-8 \mu \mathrm{m}$ 
from the self-assembly of the single $\mathrm{La}(\mathrm{OH}) \mathrm{CO}_{3}$ nanoplates via the hydrothermal reaction of bulk $\mathrm{La}_{2} \mathrm{O}_{3}$ powders with $\mathrm{NH}_{2} \mathrm{CH}_{2} \mathrm{COOH}$. Under the thermal procedure, the obtained $1 \mathrm{D}$ $\mathrm{La}(\mathrm{OH}) \mathrm{CO}_{3}$ nanostructures could be converted to porous $\mathrm{La}(\mathrm{OH})_{3}$ and $\mathrm{La}_{2} \mathrm{O}_{3}$ nanorods. The $\mathrm{La}(\mathrm{OH}) \mathrm{CO}_{3}$ was first transformed into $\mathrm{La}_{2} \mathrm{O}_{3}$ through calcination at $900{ }^{\circ} \mathrm{C}$ and then further change into hexagonal-phased $\mathrm{La}(\mathrm{OH})_{3}$ by a hydrolysis process. The doping ion obviously plays a crucial role in modifying the interesting optical properties of the produced mixed oxides. The orthorhombic-phase $\mathrm{Eu}^{3+} / \mathrm{Tb}^{3+}$ doped $\mathrm{La}_{2} \mathrm{OCO}_{3} / \mathrm{La}_{2} \mathrm{O}_{3}$ nano/microcrystals with multiform morphologies were synthesized via a homogeneous precipitation ( $\mathrm{Li}$ et al. 2010a). The multiform $\mathrm{LaCO}_{3} \mathrm{OH}$ products such as flake, flower, rhombuse, two-double hexagram, sandwichlike spindle, peach-nucleus-shaped nanocrystals obtained by changing the carbon sources $\left[\mathrm{CO}\left(\mathrm{NH}_{2}\right)_{2}, \mathrm{Na}_{2} \mathrm{CO}_{3}, \mathrm{NaHCO}_{3},\left(\mathrm{NH}_{4}\right)_{2} \mathrm{CO}_{3}\right.$, and $\left.\mathrm{NH}_{4} \mathrm{HCO}_{3}\right], \mathrm{NH}_{4}{ }^{+}, \mathrm{Na}^{+}$ions, and $\mathrm{pH}$ values of the initial solution. $\mathrm{LaCO}_{3} \mathrm{OH}$ was easily converted to $\mathrm{La}_{2} \mathrm{O}_{2} \mathrm{CO}_{3}$ and $\mathrm{La}_{2} \mathrm{O}_{3}$ under annealing at suitable temperatures. The excitation and selective emission spectroscopy were applied to the microstructures and difference in ${ }^{5} \mathrm{D}_{0} \rightarrow{ }^{7} \mathrm{~F}_{2}$ transition of $\mathrm{Eu}^{3+}$ ions in $\mathrm{La}_{2} \mathrm{O}_{2} \mathrm{CO}_{3}$ and $\mathrm{La}_{2} \mathrm{O}_{3}$ host lattices. In addition, the optical luminescence properties of 1-5 $\mathrm{mol} \% \mathrm{Eu}^{3+} / \mathrm{Tb}^{3+}$-doped $\mathrm{La}_{2} \mathrm{OCO}_{3} / \mathrm{La}_{2} \mathrm{O}_{3}$ phosphors were strongly dependent on their morphologies and sizes. Reddy et al. (Reddy, Katta and Thrimurthulu 2009) synthesized the novel nanocrystalline $\mathrm{Ce}_{1-x} \mathrm{La}_{x} \mathrm{O}_{2-\delta}(x=0.2)$ solid solutions via a modified coprecipitation. The mixed $\mathrm{Ce}_{1-x} \mathrm{La}_{x} \mathrm{O}_{2-\delta}$ nanocomposites well matched with the standard fluorite type cubic phase of $\mathrm{CeO}_{2}$. Variation in the lattice parameter of $\mathrm{CeO}_{2}$ was ascribed to the partial substitution of $\mathrm{Ce}^{4+}$ with $\mathrm{La}^{3+}$. The incorporation of $\mathrm{La}^{3+}$ into $\mathrm{CeO}_{2}$ lattice led to the lattice expansion in unit cell volume because the ionic radius of $\mathrm{La}^{3+}(0.11 \mathrm{~nm})$ is larger than $\mathrm{Ce}^{4+}$ $(0.097 \mathrm{~nm})$. The two oxidation states $\left(\mathrm{Ce}^{3+}\right.$ and $\left.\mathrm{Ce}^{4+}\right)$ coexisted in the segregation of $\mathrm{La}^{3+}$ in the $\mathrm{Ce}_{1-x} \mathrm{La}_{x} \mathrm{O}_{2-\delta}$ structure. These $\mathrm{Ce}_{1-x} \mathrm{La}_{x} \mathrm{O}_{2-\delta}$ catalysts were evaluated for OSC and $\mathrm{CO}$ oxidation activity. The nanosized Ce-La solid exhibited superior catalytic performance and thermal stability in comparison to heterostructured $\mathrm{Ce}-\mathrm{Zr}$ solid. The excellent catalytic activity of the $\mathrm{Ce}_{1-x} \mathrm{La}_{x} \mathrm{O}_{2-\delta}$ samples are originated from the features of structure, redox behavior, bulk oxygen mobility.

A variety of nanostructured metal oxide and mixed oxide materials have been synthesized by various methods, covering a wide range of compositions and tunable size/shape, especially over the past decade. In comparison, microemulsions can also be used to synthesize monodisperse mixed oxide nanocrystals with various morphologies; however, this method requires a large amount of solvent and small-scale production. In terms of size and shape control of the magnetic nanocrystals, thermal decomposition seems an improved method has been developed to date; however, this techniques often require the use of expensive organometallic or metal alkoxide precursors and performed at high temperature under argon or nitrogen atmosphere. In terms of simplicity of the synthesis, one-phase and two-phase solvo-hydrothermal surfactant-assisted methods are almost the preferred pathways for the large-scale synthesis of high-quality inorganic nanocrystals with controlled size and shape at relatively mild reaction temperature.

Eventually, the obtained metal oxide and mixed oxide nanomaterials are of great vitality and offers immense opportunities for chemistry, physics, biology, materials and engineering. Interaction among scientists with different backgrounds will undoubtedly create new science, and in particular new materials, with unforeseen technological possibilities. What is noteworthy is that such nanomaterials are likely to benefit not only the catalytic industry, but also to contribute to most aspects of the electronic and biotechnological industries. 


\section{Summary and outlook}

In summary, this chapter provides an overview of some recent progresses related to solution-based syntheses of monodisperse metal oxide and mixed oxide colloidal nanocrystals. Compared to the traditional methods such as sonochemistry, solid-phase reaction, gas-phase reaction, coprecipitation, the one-phase and two-phase solvohydrothermal surfactant-assisted pathways are much more easily controlled in the size, shape, composition, and phase structure. Several current approaches developed in our group have some conveniences including nontoxic and inexpensive reagents (e.g., inorganic metal salts as starting precursors), water as environmentally benign medium, high-yield, and large-scale products.

It is pointed out that the major interest of such metal oxide and mixed oxide nanocrystals is systematically studied their catalytic properties in our laboratory for the next time. The ability to manipulate precisely the size/shape and the surface of nanocrystals has opened up a number of potential applications for the new further materials: nanoelectronics, optics, solar cells, magnetic resonance imaging (MRI), biomedicine, etc. Considering the astonishing rate at which progress is being made on several areas, we may expect that the impact of this field of nanotechnology on our daily lives will grow markedly in the near future. Finally, we expect that this chapter would be useful to readerships and could also form the basis of a course on the nanoscale shape-controlled subject.

\section{Acknowledgment}

This work was supported by the Natural Sciences and Engineering Research Council of Canada (NSERC) through a strategic grant.

\section{References}

Abbet, S. \& U. Heiz. 2005. Nanocatalysis. Wiley-VCH Verlag GmbH \& Co. KGaA.

Alivisatos, A. P. (1996) Semiconductor Clusters, Nanocrystals, and Quantum Dots. Science, 271, 933-937.

Antonini, G. M. \& et al. (1987) Atomic Local Coordinations and Multivalent States in $\mathrm{YBa}_{2} \mathrm{Cu}_{3} \mathrm{O}_{9-\delta}$ Superconductors. EPL (Europhysics Letters), 4, 851.

Arkenbout, A. H., T. T. M. Palstra, T. Siegrist \& T. Kimura (2006) Ferroelectricity in the cycloidal spiral magnetic phase of $\mathrm{MnWO}_{4}$. Physical Review B, 74, 184431.

Auzel, F. (2003) Upconversion and Anti-Stokes Processes with $\mathrm{f}$ and $\mathrm{d}$ Ions in Solids. Chemical Reviews, 104, 139-174.

Bharati, R., R. A. Singh \& B. M. Wanklyn (1982) Electrical conduction in manganese tungstate. Journal of Physics and Chemistry of Solids, 43, 641-644.

Binnemans, K. (2009) Lanthanide-Based Luminescent Hybrid Materials. Chemical Reviews, $109,4283-4374$.

Brust, M., M. Walker, D. Bethell, D. J. Schiffrin \& R. Whyman (1994) SYNTHESIS OF THIOL-DERIVATIZED GOLD NANOPARTICLES IN A 2-PHASE LIQUIDLIQUID SYSTEM. Chem. Commun., 7, 801-802.

Bünzli, J.-C. G. (2010) Lanthanide Luminescence for Biomedical Analyses and Imaging. Chemical Reviews, 110, 2729-2755. 
Burda, C., X. Chen, R. Narayanan \& M. A. El-Sayed (2005) Chemistry and Properties of Nanocrystals of Different Shapes. Chemical Reviews, 105, 1025-1102.

Chen, S.-J., X.-T. Chen, Z. Xue, J.-H. Zhou, J. Li, J.-M. Hong \& X.-Z. You (2003) Morphology control of $\mathrm{MnWO}_{4}$ nanocrystals by a solvothermal route. Journal of Materials Chemistry, 13, 1132-1135.

Corr, S. A., M. Grossman, J. D. Furman, B. C. Melot, A. K. Cheetham, K. R. Heier \& R. Seshadri (2008) Controlled Reduction of Vanadium Oxide Nanoscrolls: Crystal Structure, Morphology, and Electrical Properties. Chemistry of Materials, 20, 63966404.

Cushing, B. L., V. L. Kolesnichenko \& C. J. O'Connor (2004) Recent Advances in the LiquidPhase Syntheses of Inorganic Nanoparticles. Chemical Reviews, 104, 3893-3946.

Ding, S.-J., D. W. Zhang, P.-F. Wang \& J.-T. Wang (2001) Preparation and photoluminescence of the Ce-, $\mathrm{Tb}$ - and Gd-doped lanthanum borophosphate phosphor. Materials Chemistry and Physics, 68, 98-104.

Dinh, C. T., Nguyen, T.D., Kleitz, F. and Do. T. O. (2009). Shape-controlled synthesis of highly crystalline titania nanocrystals, ACS nano, 3, pp. 3737-3743.

Djerdj, I., D. Arčon, Z. Jaglicíć \& M. Niederberger (2007) Nonaqueous Synthesis of Manganese Oxide Nanoparticles, Structural Characterization, and Magnetic Properties. The Journal of Physical Chemistry C, 111, 3614-3623.

Du, H., S. Wohlrab, Wei \& S. Kaskel (2007) Preparation of $\mathrm{BaTiO}_{3}$ nanocrystals using a twophase solvothermal method. Journal of Materials Chemistry, 17, 4605-4610.

Esteban-Betegón, F. t., C. Zaldo \& C. n. Cascales (2010) Hydrothermal $\mathrm{Yb}^{3+}$-Doped $\mathrm{NaGd}\left(\mathrm{WO}_{4}\right)_{2}$ Nano- and Micrometer-Sized Crystals with Preserved Photoluminescence Properties. Chemistry of Materials, 22, 2315-2324.

Etsell, T. H. \& S. N. Flengas (1970) Electrical properties of solid oxide electrolytes. Chemical Reviews, 70, 339-376.

$\mathrm{Fu}, \mathrm{Q}$. \& T. Wagner (2007) Interaction of nanostructured metal overlayers with oxide surfaces. Surface Science Reports, 62, 431-498.

Gariglio, S., M. Gabay \& J.-M. Triscone (2010) Oxide materials: Superconductivity on the other side. Nat Nano, 5, 13-14.

Garnweitner, G., M. Antonietti \& M. Niederberger (2005) Nonaqueous synthesis of crystalline anatase nanoparticles in simple ketones and aldehydes as oxygensupplying agents. Chemical Communications, 397-399.

Garnweitner, G. \& M. Niederberger (2008) Organic chemistry in inorganic nanomaterials synthesis. Journal of Materials Chemistry, 18, 1171-1182.

Ghoshal, T., S. Biswas, P. M. G. Nambissan, G. Majumdar \& S. K. De (2009) Cadmium Oxide Octahedrons and Nanowires on the Micro-Octahedrons: A Simple Solvothermal Synthesis. Crystal Growth E Design, 9, 1287-1292.

Gu, G., M. Schmid, P.-W. Chiu, A. Minett, J. Fraysse, G.-T. Kim, S. Roth, M. Kozlov, E. Munoz \& R. H. Baughman (2003) $\mathrm{V}_{2} \mathrm{O}_{5}$ nanofibre sheet actuators. Nat Mater, 2, 316319.

Guiton, B. S., Q. Gu, A. L. Prieto, M. S. Gudiksen \& H. Park (2004) Single-Crystalline Vanadium Dioxide Nanowires with Rectangular Cross Sections. Journal of the American Chemical Society, 127, 498-499. 
Hao, R., R. Xing, Z. Xu, Y. Hou, S. Gao \& S. Sun (2010) Synthesis, Functionalization, and Biomedical Applications of Multifunctional Magnetic Nanoparticles. Advanced Materials, 22, 2729-2742.

Heyer, O. \& et al. (2006) A new multiferroic material: $\mathrm{MnWO}_{4}$. Journal of Physics: Condensed Matter, 18, L471.

Jun, Y.-w., J.-s. Choi \& J. Cheon (2006a) Shape Control of Semiconductor and Metal Oxide Nanocrystals through Nonhydrolytic Colloidal Routes. Angewandte Chemie International Edition, 45, 3414-3439.

Kalai Selvan, R., A. Gedanken, P. Anilkumar, G. Manikandan \& C. Karunakaran (2009) Synthesis and Characterization of Rare Earth Orthovanadate $\left(\mathrm{RVO}_{4} ; \mathrm{R}=\mathrm{La}, \mathrm{Ce}\right.$, $\mathrm{Nd}, \mathrm{Sm}, \mathrm{Eu}, \mathrm{Gd})$ Nanorods/Nanocrystals/Nanospindles by a Facile Sonochemical Method and Their Catalytic Properties. Journal of Cluster Science, 20, 291-305.

Kamat, P. V., K. Tvrdy, D. R. Baker \& J. G. Radich (2010) Beyond Photovoltaics: Semiconductor Nanoarchitectures for Liquid-Junction Solar Cells. Chemical Reviews, 110, 6664-6688.

Kim, F., S. Kwan, J. Akana \& P. Yang (2001) Langmuir-Blodgett Nanorod Assembly. Journal of the American Chemical Society, 123, 4360-4361.

Kinge, S., M. Crego-Calama \& D. N. Reinhoudt (2008) Self-Assembling Nanoparticles at Surfaces and Interfaces. ChemPhysChem, 9, 20-42.

Kroes, G.-J., A. Gross, E.-J. Baerends, M. Scheffler \& D. A. McCormack (2002) Quantum Theory of Dissociative Chemisorption on Metal Surfaces. Accounts of Chemical Research, 35, 193-200.

Kwon, S. G. \& T. Hyeon. 2009. Kinetics of Colloidal Chemical Synthesis of Monodisperse Spherical Nanocrystals. John Wiley \& Sons, Inc.

LaMer, V. K. \& R. H. Dinegar (1950) Theory, Production and Mechanism of Formation of Monodispersed Hydrosols. Journal of the American Chemical Society, 72, 4847-4854.

Li, G., K. Chao, H. Peng, K. Chen \& Z. Zhang (2007) Low-Valent Vanadium Oxide Nanostructures with Controlled Crystal Structures and Morphologies. Inorganic Chemistry, 46, 5787-5790.

Li, G., C. Peng, C. Zhang, Z. Xu, M. Shang, D. Yang, X. Kang, W. Wang, C. Li, Z. Cheng \& J. Lin (2010a) $\mathrm{Eu}^{3+} / \mathrm{Tb}^{3+}$-Doped $\mathrm{La}_{2} \mathrm{O}_{2} \mathrm{CO}_{3} / \mathrm{La}_{2} \mathrm{O}_{3}$ Nano/Microcrystals with Multiform Morphologies: Facile Synthesis, Growth Mechanism, and Luminescence Properties. Inorganic Chemistry, 49, 10522-10535.

Li, P., C. Nan, Z. Wei, J. Lu, Q. Peng \& Y. Li (2010b) $\mathrm{Mn}_{3} \mathrm{O}_{4}$ Nanocrystals: Facile Synthesis, Controlled Assembly, and Application. Chemistry of Materials, 22, 4232-4236.

Li, P., Q. Peng \& Y. Li (2009) Dual-Mode Luminescent Colloidal Spheres from Monodisperse Rare-Earth Fluoride Nanocrystals. Advanced Materials, 21, 1945-1948.

Li, X.-L., Q. Peng, J.-X. Yi, X. Wang \& Y. Li (2006) Near Monodisperse $\mathrm{TiO}_{2}$ Nanoparticles and Nanorods. Chemistry - A European Journal, 12, 2383-2391.

Liang, X., X. Wang, Y. Zhuang, B. Xu, S. Kuang \& Y. Li (2008) Formation of $\mathrm{CeO}_{2}-\mathrm{ZrO}_{2}$ Solid Solution Nanocages with Controllable Structures via Kirkendall Effect. Journal of the American Chemical Society, 130, 2736-2737.

Liu, B., S.-H. Yu, L. Li, F. Zhang, Q. Zhang, M. Yoshimura \& P. Shen (2004) Nanorod-Direct Oriented Attachment Growth and Promoted Crystallization Processes Evidenced in Case of ZnWO4. The Journal of Physical Chemistry B, 108, 2788-2792. 
Liu, J. \& Y. Li (2007) General synthesis of colloidal rare earth orthovanadate nanocrystals. Journal of Materials Chemistry, 17, 1797-1803.

Livage, J. (1991) Vanadium pentoxide gels. Chemistry of Materials, 3, 578-593.

Lu, J. G., P. Chang \& Z. Fan (2006) Quasi-one-dimensional metal oxide materials--Synthesis, properties and applications. Materials Science and Engineering: R: Reports, 52, 49-91.

Lutta, S. T., H. Dong, P. Y. Zavalij \& M. S. Whittingham (2005) Synthesis of vanadium oxide nanofibers and tubes using polylactide fibers as template. Materials Research Bulletin, 40, 383-393.

Mai, H.-X., Y.-W. Zhang, R. Si, Z.-G. Yan, L.-d. Sun, L.-P. You \& C.-H. Yan (2006) HighQuality Sodium Rare-Earth Fluoride Nanocrystals: $\square$ Controlled Synthesis and Optical Properties. Journal of the American Chemical Society, 128, 6426-6436.

MalenfantPatrick, R. L., J. Wan, S. T. Taylor \& M. Manoharan (2007) Self-assembly of an organic-inorganic block copolymer for nano-ordered ceramics. Nat Nano, 2, 43-46.

Mao, Y., T.-J. Park \& S. S. Wong (2005) Synthesis of classes of ternary metal oxide nanostructures. Chemical Communications, 5721-5735.

Mao, Y., T.-J. Park, F. Zhang, H. Zhou \& S. S. Wong (2007) Environmentally Friendly Methodologies of Nanostructure Synthesis. Small, 3, 1122-1139.

Meiser, F., C. Cortez \& F. Caruso (2004) Biofunctionalization of Fluorescent Rare-EarthDoped Lanthanum Phosphate Colloidal Nanoparticles. Angewandte Chemie International Edition, 43, 5954-5957.

Mrabet, D., M. H. Zahedi-Niaki \& T.-O. Do (2008) Synthesis of Nanoporous Network Materials with High Surface Areas from the Cooperative Assemblage of AlkylChain-Capped Metal/Metal Oxide Nanoparticles. The Journal of Physical Chemistry C, 112, 7124-7129.

Muster, J., G. T. Kim, V. Krstić, J. G. Park, Y. W. Park, S. Roth \& M. Burghard (2000) Electrical Transport Through Individual Vanadium Pentoxide Nanowires. Advanced Materials, 12, 420-424.

Na, H. B., I. C. Song \& T. Hyeon (2009) Inorganic Nanoparticles for MRI Contrast Agents. Advanced Materials, 21, 2133-2148.

Nagarajan, R. 2008. Nanoparticles: Building Blocks for Nanotechnology. In Nanoparticles: Synthesis, Stabilization, Passivation, and Functionalization, 2-14. American Chemical Society.

Nguyen, T.-D., C.-T. Dinh \& T.-O. Do (2009a) Monodisperse Samarium and Cerium Orthovanadate Nanocrystals and Metal Oxidation States on the Nanocrystal Surface. Langmuir, 25, 11142-11148.

Nguyen, T.-D., C.-T. Dinh \& T.-O. Do (2010) Shape- and Size-Controlled Synthesis of Monoclinic ErOOH and Cubic $\mathrm{Er}_{2} \mathrm{O}_{3}$ from Micro- to Nanostructures and Their Upconversion Luminescence. ACS Nano, 4, 2263-2273.

Nguyen, T.-D., C.-T. Dinh \& T.-O. Do (2011a) Two-Phase Synthesis of Colloidal AnnularShaped $\mathrm{CexLa}_{1-\mathrm{x}} \mathrm{CO}_{3} \mathrm{OH}$ Nanoarchitectures Assemblied from Small Particles and Their Thermal Conversion to Derived Mixed Oxides. Inorganic Chemistry, 2011, 50, 1309-1320.

Nguyen, T.-D., C.-T. Dinh, D.-T. Nguyen \& T.-O. Do (2009b) A Novel Approach for Monodisperse Samarium Orthovanadate Nanocrystals: Controlled Synthesis and Characterization. The Journal of Physical Chemistry C, 113, 18584-18595. 
Nguyen, T.-D. \& T.-O. Do (2009a) General Two-Phase Routes to Synthesize Colloidal Metal Oxide Nanocrystals: Simple Synthesis and Ordered Self-Assembly Structures. The Journal of Physical Chemistry C, 113, 11204-11214.

Nguyen, T.-D. \& T.-O. Do (2009b) Solvo-Hydrothermal Approach for the Shape-Selective Synthesis of Vanadium Oxide Nanocrystals and Their Characterization. Langmuir, 25, 5322-5332.

Nguyen, T.-D., D. Mrabet \& T.-O. Do (2008) Controlled Self-Assembly of $\mathrm{Sm}_{2} \mathrm{O}_{3}$ Nanoparticles into Nanorods: Simple and Large Scale Synthesis using Bulk $\mathrm{Sm}_{2} \mathrm{O}_{3}$ Powders. The Journal of Physical Chemistry C, 112, 15226-15235.

Nguyen, T.-D., D. Mrabet, T.-T.-D. Vu, C.-T. Dinh \& T.-O. Do (2011b) Biomolecule-assisted route for shape-controlled synthesis of single-crystalline $\mathrm{MnWO}_{4}$ nanoparticles and spontaneous assembly of polypeptide-stabilized mesocrystal microspheres. CrystEngComm, 2011, 13, 1450-1460.

Norris, D. J., A. L. Efros \& S. C. Erwin (2008) Doped Nanocrystals. Science, 319, 1776-1779.

Pan, D., Q. Wang, S. Jiang, X. Ji \& L. An (2005a) Synthesis of Extremely Small CdSe and Highly Luminescent CdSe/CdS Core-Shell Nanocrystals via a Novel Two-Phase Thermal Approach. Advanced Materials, 17, 176-179.

Pan, D., Q. Wang, J. Pang, S. Jiang, X. Ji \& L. An (2006) Semiconductor “Nano-Onions" with Multifold Alternating CdS/CdSe or CdSe/CdS Structure. Chemistry of Materials, 18, 4253-4258.

Pan, D., N. Zhao, Q. Wang, S. Jiang, X. Ji \& L. An (2005b) Facile Synthesis and Characterization of Luminescent $\mathrm{TiO}_{2}$ Nanocrystals. Advanced Materials, 17, 19911995.

Park, J., J. Joo, S. G. Kwon, Y. Jang \& T. Hyeon (2007) Synthesis of Monodisperse Spherical Nanocrystals. Angewandte Chemie International Edition, 46, 4630-4660.

Pileni, M. P. (2007) Control of the Size and Shape of Inorganic Nanocrystals at Various Scales from Nano to Macrodomains. The Journal of Physical Chemistry C, 111, 90199038.

Pinna, N., M. Willinger, K. Weiss, J. Urban \& R. Schlögl (2003) Local Structure of Nanoscopic Materials: $\square \mathrm{V}_{2} \mathrm{O}_{5}$ Nanorods and Nanowires. Nano Letters, 3, 1131-1134.

Poizot, P., S. Laruelle, S. Grugeon, L. Dupont \& J. M. Tarascon (2000) Nano-sized transitionmetal oxides as negative-electrode materials for lithium-ion batteries. Nature, 407, 496-499.

Qu, W., W. Wlodarski \& J.-U. Meyer (2000) Comparative study on micromorphology and humidity sensitive properties of thin-film and thick-film humidity sensors based on semiconducting $\mathrm{MnWO}_{4}$. Sensors and Actuators B: Chemical, 64, 76-82.

Rao, C. N. R., A. Müller \& A. K. Cheetham. 2005. Nanomaterials - An Introduction. WileyVCH Verlag $\mathrm{GmbH} \& \mathrm{Co}$. KGaA.

Reddy, B. M., L. Katta \& G. Thrimurthulu (2009) Novel Nanocrystalline $\mathrm{Ce}_{1-x} \mathrm{LaxO}_{2-\delta}(\mathrm{x}=$ $0.2)$ Solid Solutions: Structural Characteristics and Catalytic Performance. Chemistry of Materials, 22, 467-475.

Redl, F. X., K. S. Cho, C. B. Murray \& S. O'Brien (2003) Three-dimensional binary superlattices of magnetic nanocrystals and semiconductor quantum dots. Nature, 423, 968-971.

Schmid, G. 2005. General Introduction. Wiley-VCH Verlag GmbH \& Co. KGaA. 
Searcy, A. W. (1983) The equilibrium shapes of crystals and of cavities in crystals. Journal of Solid State Chemistry, 48, 93-99.

Sellinger, A., P. M. Weiss, A. Nguyen, Y. Lu, R. A. Assink, W. Gong \& C. J. Brinker (1998) Continuous self-assembly of organic-inorganic nanocomposite coatings that mimic nacre. Nature, 394, 256-260.

Seshadri, R. 2005. Oxide Nanoparticles. Wiley-VCH Verlag GmbH \& Co. KGaA.

Shah, P. R., M. M. Khader, J. M. Vohs \& R. J. Gorte (2008) A Comparison of the Redox Properties of Vanadia-Based Mixed Oxides. The Journal of Physical Chemistry C, 112, 2613-2617.

Shi, H., L. Qi, J. Ma \& H. Cheng (2003a) Polymer-Directed Synthesis of Penniform $\mathrm{BaWO}_{4}$ Nanostructures in Reverse Micelles. Journal of the American Chemical Society, 125, 3450-3451.

Shi, H., L. Qi, J. Ma, H. Cheng \& B. Zhu (2003b) Synthesis of Hierarchical Superstructures Consisting of $\mathrm{BaCrO} 4$ Nanobelts in Catanionic Reverse Micelles. Advanced Materials, 15, 1647-1651.

Skrabalak, S. E. \& Y. Xia (2009) Pushing Nanocrystal Synthesis toward Nanomanufacturing. ACS Nano, 3, 10-15.

Sorensen, C. M. 2009. Particles as Molecules. John Wiley \& Sons, Inc.

Spahr, M. E., P. Bitterli, R. Nesper, M. Müller, F. Krumeich \& H. U. Nissen (1998) RedoxActive Nanotubes of Vanadium Oxide. Angewandte Chemie International Edition, 37, 1263-1265.

Su, L. T., A. I. Y. Tok, Y. Zhao, N. Ng \& F. Y. C. Boey (2009) Synthesis and Electron-Phonon Interactions of Ce3+-Doped YAG Nanoparticles. The Journal of Physical Chemistry C, 113, 5974-5979.

Sun, C., J. Sun, G. Xiao, H. Zhang, X. Qiu, H. Li \& L. Chen (2006a) Mesoscale Organization of Nearly Monodisperse Flowerlike Ceria Microspheres. The Journal of Physical Chemistry B, 110, 13445-13452.

Sun, L., Q. Guo, X. Wu, S. Luo, W. Pan, K. Huang, J. Lu, L. Ren, M. Cao \& C. Hu (2006b) Synthesis and Photoluminescent Properties of Strontium Tungstate Nanostructures. The Journal of Physical Chemistry C, 111, 532-537.

Sun, Y., H. Liu, X. Wang, X. Kong \& H. Zhang (2006c) Optical Spectroscopy and Visible Upconversion Studies of $\mathrm{YVO}_{4}: \mathrm{Er}^{3+}$ Nanocrystals Synthesized by a Hydrothermal Process. Chemistry of Materials, 18, 2726-2732.

Tenne, R. (2004) Materials physics: Doping control for nanotubes. Nature, 431, 640-641.

Thongtem, S., S. Wannapop \& T. Thongtem (2009) Characterization of $\mathrm{MnWO}_{4}$ with flowerlike clusters produced using spray pyrolysis. Transactions of Nonferrous Metals Society of China, 19, s100-s104.

Tong, W., L. Li, W. Hu, T. Yan, X. Guan \& G. Li (2010) Kinetic Control of $\mathrm{MnWO}_{4}$ Nanoparticles for Tailored Structural Properties. The Journal of Physical Chemistry C, $114,15298-15305$.

Wachs, I. E. (2005) Recent conceptual advances in the catalysis science of mixed metal oxide catalytic materials. Catalysis Today, 100, 79-94.

Wang, D.-S., T. Xie, Q. Peng, S.-Y. Zhang, J. Chen \& Y.-D. Li (2008) Direct Thermal Decomposition of Metal Nitrates in Octadecylamine to Metal Oxide Nanocrystals. Chemistry - A European Journal, 14, 2507-2513. 
Wang, M., J.-L. Liu, Y.-X. Zhang, W. Hou, X.-L. Wu \& S.-K. Xu (2009) Two-phase solvothermal synthesis of rare-earth doped NaYF4 upconversion fluorescent nanocrystals. Materials Letters, 63, 325-327.

Wang, Q., D. Pan, S. Jiang, X. Ji, L. An \& B. Jiang (2005a) A New Two-Phase Route to HighQuality CdS Nanocrystals. Chemistry - A European Journal, 11, 3843-3848.

Wang, X., J. Zhuang, Q. Peng \& Y. Li (2005b) A general strategy for nanocrystal synthesis. Nature, 437, 121-124.

Wang, X., J. Zhuang, Q. Peng \& Y. Li (2006) Hydrothermal Synthesis of Rare-Earth Fluoride Nanocrystals. Inorganic Chemistry, 45, 6661-6665.

Watzky, M. A. \& R. G. Finke (1997) Transition Metal Nanocluster Formation Kinetic and Mechanistic Studies. A New Mechanism When Hydrogen Is the Reductant: Slow, Continuous Nucleation and Fast Autocatalytic Surface Growth. Journal of the American Chemical Society, 119, 10382-10400.

Xia, Y., Y. Xiong, B. Lim \& S. E. Skrabalak (2009) Shape-Controlled Synthesis of Metal Nanocrystals: Simple Chemistry Meets Complex Physics?. Angewandte Chemie International Edition, 48, 60-103.

Xie, J., Q. Wu, D. Zhang \& Y. Ding (2009) Biomolecular-Induced Synthesis of SelfAssembled Hierarchical $\mathrm{La}(\mathrm{OH}) \mathrm{CO}_{3}$ One-Dimensional Nanostructures and Its Morphology-Held Conversion toward $\mathrm{La}_{2} \mathrm{O}_{3}$ and $\mathrm{La}(\mathrm{OH})_{3}$. Crystal Growth \& Design, 9, 3889-3897.

Xie, R.-C. \& J. Shang (2007) Morphological control in solvothermal synthesis of titanium oxide. Journal of Materials Science, 42, 6583-6589.

Xing, Y., S. Song, J. Feng, Y. Lei, M. Li \& H. Zhang (2008) Microemulsion-mediated solvothermal synthesis and photoluminescent property of 3D flowerlike $\mathrm{MnWO}_{4}$ micro/nanocomposite structure. Solid State Sciences, 10, 1299-1304.

Xu, Z., X. Kang, C. Li, Z. Hou, C. Zhang, D. Yang, G. Li \& J. Lin (2010) $\operatorname{Ln}^{3+}$ (Ln = Eu, Dy, $\mathrm{Sm}$, and Er) Ion-Doped $\mathrm{YVO}_{4} \mathrm{Nano} /$ Microcrystals with Multiform Morphologies: Hydrothermal Synthesis, Growing Mechanism, and Luminescent Properties. Inorganic Chemistry, 49, 6706-6715.

Yan, T., X. Wang, J. Long, H. Lin, R. Yuan, W. Dai, Z. Li \& X. Fu (2008) Controlled preparation of $\mathrm{In}_{2} \mathrm{O}_{3}, \mathrm{InOOH}$ and $\mathrm{In}(\mathrm{OH})_{3}$ via a one-pot aqueous solvothermal route. New Journal of Chemistry, 32, 1843-1846.

Yan, Z.-G. \& C.-H. Yan (2008) Controlled synthesis of rare earth nanostructures. Journal of Materials Chemistry, 18, 5046-5059.

Yin, Y. \& A. P. Alivisatos (2005) Colloidal nanocrystal synthesis and the organic-inorganic interface. Nature, 437, 664-670.

Ying, J. Y. (2000) Nanostructural tailoring: Opportunities for molecular engineering in catalysis. AIChE Journal, 46, 1902-1906.

Yu, C., M. Yu, C. Li, C. Zhang, P. Yang \& J. Lin (2008) Spindle-like Lanthanide Orthovanadate Nanoparticles: Facile Synthesis by Ultrasonic Irradiation, Characterization, and Luminescent Properties. Crystal Growth \& Design, 9, 783-791.

Zhang, F., M. Y. Sfeir, J. A. Misewich \& S. S. Wong (2008a) Room-Temperature Preparation, Characterization, and Photoluminescence Measurements of Solid Solutions of Various Compositionally-Defined Single-Crystalline Alkaline-Earth-Metal Tungstate Nanorods. Chemistry of Materials, 20, 5500-5512. 
Zhang, F., Y. Yiu, M. C. Aronson \& S. S. Wong (2008b) Exploring the Room-Temperature Synthesis and Properties of Multifunctional Doped Tungstate Nanorods. The Journal of Physical Chemistry C, 112, 14816-14824.

Zhang, J., S. Ohara, M. Umetsu, T. Naka, Y. Hatakeyama \& T. Adschiri (2007a) Colloidal Ceria Nanocrystals: A Tailor-Made Crystal Morphology in Supercritical Water. Advanced Materials, 19, 203-206.

Zhang, L., C. Lu, Y. Wang \& Y. Cheng (2007b) Hydrothermal synthesis and characterization of $\mathrm{MnWO}_{4}$ nanoplates and their ionic conductivity. Materials Chemistry and Physics, $103,433-436$.

Zhang, Q., X. Chen, Y. Zhou, G. Zhang \& S.-H. Yu (2007c) Synthesis of ZnWO4@MWO4 (M $=\mathrm{Mn}, \mathrm{Fe}$ ) Core-Shell Nanorods with Optical and Antiferromagnetic Property by Oriented Attachment Mechanism. The Journal of Physical Chemistry C, 111, 39273933.

Zhao, N., W. Nie, X. Liu, S. Tian, Y. Zhang \& X. Ji (2008) Shape- and Size-Controlled Synthesis and Dependent Magnetic Properties of Nearly Monodisperse $\mathrm{Mn}_{3} \mathrm{O}_{4}$ Nanocrystals. Small, 4, 77-81.

Zhao, N., W. Nie, J. Mao, M. Yang, D. Wang, Y. Lin, Y. Fan, Z. Zhao, H. Wei \& X. Ji (2010) A General Synthesis of High-Quality Inorganic Nanocrystals via a Two-Phase Method. Small, 6, 2558-2565.

Zhao, N., D. Pan, W. Nie \& X. Ji (2006) Two-Phase Synthesis of Shape-Controlled Colloidal Zirconia Nanocrystals and Their Characterization. Journal of the American Chemical Society, 128, 10118-10124.

Zhou, H., Y. Yiu, M. C. Aronson \& S. S. Wong (2008a) Ambient template synthesis of multiferroic $\mathrm{MnWO}_{4}$ nanowires and nanowire arrays. Journal of Solid State Chemistry, 181, 1539-1545.

Zhou, Y.-X., H.-B. Yao, Q. Zhang, J.-Y. Gong, S.-J. Liu \& S.-H. Yu (2009) Hierarchical FeWO4 Microcrystals: Solvothermal Synthesis and Their Photocatalytic and Magnetic Properties. Inorganic Chemistry, 48, 1082-1090.

Zhou, Y.-X., Q. Zhang, J.-Y. Gong \& S.-H. Yu (2008b) Surfactant-Assisted Hydrothermal Synthesis and Magnetic Properties of Urchin-like $\mathrm{MnWO}_{4}$ Microspheres. The Journal of Physical Chemistry C, 112, 13383-13389. 


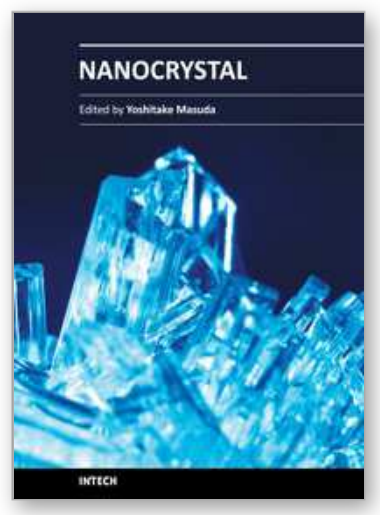

\author{
Nanocrystal \\ Edited by Dr. Yoshitake Masuda
}

ISBN 978-953-307-199-2

Hard cover, 494 pages

Publisher InTech

Published online 28, June, 2011

Published in print edition June, 2011

We focused on cutting-edge science and technology of Nanocrystals in this book. â€œNanocrystalâ€ is expected to lead to the creation of new materials with revolutionary properties and functions. It will open up fresh possibilities for the solution to the environmental problems and energy problems. We wish that this book contributes to bequeath a beautiful environment and valuable resources to subsequent generations.

\title{
How to reference
}

In order to correctly reference this scholarly work, feel free to copy and paste the following:

Thanh-Dinh Nguyen and Trong-On Do (2011). Size- and Shape-Controlled Synthesis of Monodisperse Metal Oxide and Mixed Oxide Nanocrystals, Nanocrystal, Dr. Yoshitake Masuda (Ed.), ISBN: 978-953-307-199-2, InTech, Available from: http://www.intechopen.com/books/nanocrystal/size-and-shape-controlled-synthesis-ofmonodisperse-metal-oxide-and-mixed-oxide-nanocrystals

\section{INTECH}

open science | open minds

\author{
InTech Europe \\ University Campus STeP Ri \\ Slavka Krautzeka 83/A \\ 51000 Rijeka, Croatia \\ Phone: +385 (51) 770447 \\ Fax: +385 (51) 686166 \\ www.intechopen.com
}

\author{
InTech China \\ Unit 405, Office Block, Hotel Equatorial Shanghai \\ No.65, Yan An Road (West), Shanghai, 200040, China \\ 中国上海市延安西路65号上海国际贵都大饭店办公楼 405 单元 \\ Phone: +86-21-62489820 \\ Fax: +86-21-62489821
}


(C) 2011 The Author(s). Licensee IntechOpen. This chapter is distributed under the terms of the Creative Commons Attribution-NonCommercialShareAlike-3.0 License, which permits use, distribution and reproduction for non-commercial purposes, provided the original is properly cited and derivative works building on this content are distributed under the same license. 